Revista lus et Praxis, Año 24, No 2, 2018, pp. 469 - 512

ISSN 0717 - 2877

Universidad de Talca - Facultad de Ciencias Jurídicas y Sociales

La evolución de la custodia unilateral conforme a los principios de interés superior del niño Rodrigo Barcia Lehmann

Trabajo recibido el 1 de agosto de 2016 y aprobado el 12 de diciembre de 2017

\title{
La evolución de la custodia unilateral conforme a los principios de interés superior del niño y corresponsabilidad de los padres*
}

\author{
THE EVOLUTION OF UNILATERAL CUSTODY ACCORDING TO THE PRINCIPLES OF \\ THE BEST INTERESTS OF THE CHILD AND THE CO-RESPONSIBILITY OF THE PARENTS
}

Rodrigo Barcia LehMANn*

RESUMEN

El presente trabajo aborda cómo los principios de interés superior del niño, en un comienzo, y, de corresponsabilidad, de forma posterior, han ido modificando las formas de custodia unilateral. Así, el Derecho ha evolucionado desde formas judiciales de custodia unilateral a favor, del padre, y luego a favor de la madre, a formas de asignación unilateral regidas por los susodichos principios. El presente trabajo destaca que, dada nuestra regulación, el establecimiento de deberes/facultades específicos para el padre no custodio obedece a un imperativo legal que lamentablemente, y a pesar de la Reforma de la Ley № 20.680, no se está cumpliendo. Para el establecimiento de facultades/deberes del padre no custodio los tribunales deben recurrir a la regulación estatutaria de infancia, concretizando estas facultades/deberes a través de la $R D R$.

\section{ABSTRACT}

The present work deals with how the principles of the best interest of the child, in a beginning, and, of co-responsibility, of a later form, have been modifying the forms of unilateral custody. Thus, law has evolved from unilateral judicial custody in favor of the father, and then in favor of the mother, to forms of unilateral allocation governed by the aforementioned principles. The present work emphasizes that, given our regulation, the establishment of specific duties/powers for the non-custodial parent obeys a legal imperative that unfortunately, and despite the Reform of Law No. 20,680, is not being fulfilled. For the establishment of faculties/duties for the non-custodial parent, the courts must resort to statutory regulation of childhood, concretizing these faculties/ duties through the direct relationship and regulate.

\section{Palabras Clave}

Cuidado personal, relación directa y regular, igualdad de los padres, interés superior del niño y guarda y custodia

\footnotetext{
* El presente artículo forma parte de la investigación titulada: "Facultades y deberes del padre no custodio", Proyecto Fondecyt № 1150454, 2015-2016. Mi especial agradecimiento a Flavia Urqueta Sánchez, ayudante de investigación de la UFT.

** Licenciado en Ciencias Jurídicas y Sociales, MBA Economía y Dirección Internacional de Empresas, MEDI, Universidad Autónoma de Madrid, 1997; European Master in Law and Economics, Complutense y Hamburg Universität, 1998 y Doctor en Derecho Civil, Universidad Complutense de Madrid, 2002. Profesor titular, Facultad de Derecho, Universidad FinisTerrae. Correo electrónico: rbarcia@uft.cl.
} 
KEY WORDS

Child custody, direct relationship and regulate, equality of parents, the best interests of the child and custody

\section{Introducción}

Los países que han adoptado sistemas de responsabilidad parental compartida, o incluso de custodia compartida, en su momento establecieron regímenes de asignación de facultades y derechos de filiación a favor del padre y luego a favor de la madre ${ }^{1}$. Y como estadio intermedio, entre ambos extremos, estos regímenes, en su mayoría, otorgaron al padre no custodio primero por vía jurisprudencia y, luego, mediante reformas legales, deberes/facultades exclusivos, conforme al principio de igualdad de los padres², como una forma de manifestación del principio del interés superior del niño. El establecimiento de deberes/ facultades exclusivos para el padre no custodio en los hechos condujo a que estos regímenes fueran evolucionando hacia regímenes de corresponsabilidad

\footnotetext{
1 En este trabajo se rehúye la utilización de la expresión deberes-facultades que, aunque más exacta, no se refiere al tema del presente artículo: determinar las facultades y derechos tienen los padres no custodios, conforme al interés superior. Para una terminología adecuada como regla general en la materia se debe recurrir a las nociones de deber -que se ve representado fundamentalmente por el deber de cuidado de los padres respecto de sus hijos-, derecho o privilegio-que representa el derecho de crianza y educación preferente de los padres respecto de sus hijos- y responsabilidad -que es contrario a la discrecionalidad en las facultades y derechos de los padres respecto de sus hijos-. EsPejo (2016), p. 209. La referencia a las facultades y derechos de los padres con relación a los hijos recibe distintos nombres en los distintos ordenamientos jurídicos. En el presente trabajo se recurre a la terminología propia de cada país, que no coincide necesariamente con la nuestra. El ejemplo más evidente de ello es la patria potestad, que entre nosotros atiende a los aspectos patrimoniales, pero en el Derecho español y en el francés, antes de ser dejada sin efecto, afecta y afectaba aspectos patrimoniales y personales.

2 No es del caso tratar acá la igualdad entre los padres, como un principio de derecho de la infancia por cuanto nuestra doctrina hace tiempo viene ocupándose de ello. La igualdad entre los cónyuges ya era el principio inspirador de la Ley $N^{0}$ 18.802, que como destacara Merino terminaría con la potestad marital, que regulaba el exartículo 132 del CCch. Veloso sería una de las primeras autoras en tratar la no discriminación relacionada con la igualdad, señalando que: "por ello además de los cambios legislativos a que están obligados los Estados, se exige asumir programas y políticas activas con el propósito de lograr la igualdad". En torno a la igualdad, como principio rector del Derecho de familia, Domínguez señala que: "a ella pertenece también la paulatina igualación de los derechos de los padres respecto de sus hijos que, en el hecho, ha supuesto una mejora de la situación jurídica de la madre en cuanto ha atenuado, incluso suprimido, la antigua potestad paternal". A su vez, Corral entiende que uno de los sustentos de la Reforma de la $L P G$ era la igualdad entre hombres y mujeres, como se aprecia de la derogación del adulterio penal y la equiparación entre el adulterio civil del marido y de la mujer. Y Lepin agrega, siguiendo a la doctrina española, que el Derecho de familia ha mutado desde un Derecho eminentemente jerárquico a uno igualitario y asociativo. Merino (1990), pp. 9-10; Veloso (1998), p. 42; Domínguez (2005), pp. 211-212; Corral (2007), p. 25 y Lepin (2014), pp. 24-40.
} 
conjunta ${ }^{3}$. Ello sucedió antes que muchos de dichos ordenamientos jurídicos se inclinaran definitivamente por la custodia compartida a través de reformas legales. Chile, a raíz de la Reforma de 2013, se encuentra en un estadio intermedio, por cuanto dicha ley suprimió la regla de la superioridad materna y ha aumentado sustancialmente los deberes/facultades del padre no custodio. El presente trabajo aborda la evolución del Derecho de la infancia desde sistemas de custodia unilateral a sistemas intermedios de corresponsabilidad. Y dentro de esta evolución del Derecho de infancia presenta los principales retos del Derecho de infancia chileno, que son dos: el desarrollo de deberes/facultades conjuntos, propios del padre no custodio y la necesidad de facultar a los jueces para decretar el cuidado personal compartido con oposición de uno de los padres.

Sin perjuicio de lo anterior, esta Reforma ha sido deficientemente implementada por los Tribunales de Familia. Una eventual explicación de su fracaso es la falta de una teoría que sea capaz de implementarla. El presente trabajo afronta este reto, y para ello se comienza analizando el interés superior del niño con relación a la igualdad de los padres (secciones II y III), para luego analizar cómo opera la corresponsabilidad, respecto del padre no custodio, conforme a un Derecho que no transgrede los principios de interés superior de los hijos y corresponsabilidad de los padres (sección IV) y, finalmente, se señalan algunas conclusiones (sección V).

\section{Cómo se aplica el interés superior del niño respetando el principio de la igualdad de los padres: desde una concepción de derechos y facultades desnudos para el padre no custodio hasta sistemas de custodia conjunta}

A continuación se destaca como los principios de la igualdad de los padres e interés superior del niño están íntimamente ligados. Dicha relación ha conducido a diversos ordenamientos jurídicos a transitar desde figuras que consagran

\footnotetext{
${ }^{3}$ La referencia a las facultades y derechos de los padres con relación a los hijos recibe distintos nombres en los distintos ordenamientos jurídicos. En el presente trabajo se recurre a la terminología propia de cada país, que no coincide necesariamente con la nuestra. El ejemplo más evidente de ello es la patria potestad, que entre nosotros atiende a los aspectos patrimoniales, pero en el Derecho español y en el francés, antes de ser dejada sin efecto, afecta y afectaba aspectos patrimoniales y personales. En este trabajo se rehúye la utilización de la expresión deberes- facultades, que aunque más exacta, no se refiere al tema del presente artículo: determinar las facultades y derechos tienen los padres no custodios, conforme al interés superior. Para una terminología adecuada como regla general en la materia se debe recurrir a las nociones de deber -que se ve representado fundamentalmente por el deber de cuidado de los padres respecto de sus hijos-, derecho o privilegio-que representa el derecho de crianza y educación preferente de los padres respecto de sus hijos- y responsabilidad -que es contrario a la discrecionalidad en las facultades y derechos de los padres respecto de sus hijos-. Ver: EsPejO (2016), p. 209.
} 
derechos y facultades para uno de los padres, en principio a favor del padre y luego de la madre, hacia sistemas de custodia conjunta o cuidado compartido.

\section{Formas de asignación de facultades y derechos de filiación que transgreden el interés superior del niño: una concepción de derechos y facultades desnudos para el padre no custodio}

El Derecho de la Infancia ha tenido una evolución similar en el Derecho comparado. Las primeras regulaciones en torno a los derechos y facultades de filiación de padres que estaban separados, se resolvía conforme a criterios valóricos, que se consideraban de orden superior. De esta forma se establecían soluciones de acuerdo a la calidad matrimonial o no de los hijos, admitiendo varias conceptualizaciones de los niños, como legítimos, ilegítimos y naturales, entre nosotros; por edades o que se inclinaban derechamente a favor de la madre; pero por sobre todo los distintos ordenamientos jurídicos buscaban un orden en la familia que subsumiera lo que la sociedad entendía por orden social. Por ello, en principio, el poder se concentraba en el marido, es decir, en el padre; y luego cuando comienza el proceso de emancipación de la mujer, es a ésta a la que se le asignan las facultades y derechos de filiación, como una forma de mantención de la autoridad de los padres en la familia ${ }^{4}$. En este modelo autoritario, lo que se hace es reemplazar la autoridad del padre -que mantenía su poder sobre los hijos legítimos a través de la patria potestad- y sobre la cónyuge a través de la potestad marital, por la autoridad de la madre a través de la regla de la superioridad materna respecto de los hijos ${ }^{5}$. Ambas

\footnotetext{
${ }^{4}$ Así, Guilarte señala que en España: “...el artículo 159 del Código Civil, en relación con la guarda y custodia, establecía que, si los padres viven separados y no decidieren de común acuerdo, los hijos e hijas menores de 7 años quedarían al cuidado de la madre, salvo que el juez por motivos especiales proveyere de otro modo. Este proyecto, discriminatorio para los padres de los hijos e hijas menores de 7 años, fue modificado por la Ley № 11/1990, de 15 de octubre de Reforma del Código Civil en aplicación del principio de no discriminación por razón de sexo que le dio la redacción actual y que suprime el criterio legal de atribución de la guarda a la madre, si se trata de hijos menores de 7 años. El Código Civil español limitaba la coparentalidad en el ejercicio a los supuestos de convivencia y para las situaciones de ruptura preveía el ejercicio exclusivo de la patria potestad que correspondía al progenitor en cuya compañía quedaban los hijos, con lo que se pretendía asegurar la unidad de dirección y preservar a los menores de posibles conflictos. Este esquema legal no responde a la nueva realidad familiar, caracterizada por un número creciente de divorcios y la normalización social de las rupturas, ya no se trata de mantener a los menores alejados del conflicto, sino de garantizar su derecho a relacionarse y a ser educado por sus dos padres". GuILARTE (2014), pp. 21-22.

${ }^{5}$ Guilarte se refiere a estos criterios históricos en España en los siguientes términos: "a lo largo de los años, el interés del menor se ha personificado en distintos criterios que facilitaban la adopción del sistema de guarda y custodia. Así, y sin ánimo de exhaustividad pueden citarse: a) La preferencia de la madre para el cuidado de los hijos de corta edad: la madre por el hecho de serlo está mejor cualificada que el padre para atender el cuidado de los hijos pequeños, de manera que se atribuirá la guarda a aquélla,
} 
reglas se sustentaron aparentemente en aspectos sociales y biológicos, pero en realidad simplemente escondían un claro sesgo ideológico.

Finalmente, se desecha la regla de la superioridad materna para otorgar el cuidado personal a uno de los padres, conforme al interés superior del niño ${ }^{6}$. La solución de otorgar exclusivamente los derechos de filiación a un padre, aun sustentándose en el principio del interés superior del niño, hace algún tiempo en el Derecho comparado se ha calificado como una regla inadecuada, por cuanto el padre no custodio se convierte en un visitador, más que un padre o una madre que participe en la crianza y educación de sus hijos. Frente a esta crítica los modelos de asignación unilateral, conforme al interés superior, han ido evolucionando en dos estadios ${ }^{7}$. Conforme al primero se otorgan facultades y derechos al padre no custodio para luego, en un segundo estadio, establecer regímenes supletorios y generales de custodia o responsabilidad compartida, por una parte, o de cuidado compartido, por la otra ${ }^{8}$. A continuación se analizará

a no ser que se demuestre su concreta incapacidad (enfermedades, adicciones, conducta desordenada o irregular). Preferencia recogida en el Principio sexto de la Declaración de los Derechos del Niño que expresamente establece que salvo circunstancias excepcionales, no deberá separarse al niño de corta edad de su madre. b) La estabilidad del menor o el establecimiento del status quo: por regla general nuestros Tribunales vienen valorando negativamente, de cara al equilibrio y normal desarrollo de los menores, tanto en la esfera emocional como escolar como social, el cambio en la situación fáctica de los menores (SAP $\left(1^{\text {a }}\right)$ de 2 de julio de 2007), de manera que atribuyen la guarda y custodia al dador de los cuidados básicos del menor, la persona que asumió el cuidado diario y desarrolló con él un vínculo más fuerte. c) Mantenimiento de las relaciones con ambos progenitores: el artículo 9.3 de la Convención sobre los Derechos del niño obligan a los Estados partes a respetar el derecho del niño que esté separado de uno o de ambos padres a mantener relaciones personales y cuidado directo con ambos de modo regular, salvo si ello es contrario al interés del niño. Este es el criterio prevalente en aquellos ordenamientos jurídicos que introducen el modelo de custodia compartida como modelo principal, salvo que el interés del menor requiera una custodia exclusiva. d) El bienestar emocional del menor: se traen aquí las conclusiones alcanzadas en la moderna psicología que mantienen que lo más importante para el adecuado desarrollo del menor en la actualidad como para su futuro como adulto es su bienestar afectivo y emocional". GUILARTE (2014), p. 55.

${ }^{6}$ En los Estados Unidos de América, la regla de la $<<$ tender years presupmption $>>$ ha sido totalmente dejada de lado. Así, en la Ley del Estado de Arkansas la custodia debe concederse, sin atener ni a la edad ni al sexo de los padres, y la Corte en la asignación de derecho de filiación solo debe considerar el $<<$ the welfare and best interest of the children $>>$.

7 A pesar de que nuestro modelo de asignación de facultades y derechos de filiación es indistinto, ya antes de la Reforma algunos autores criticaban el referido modelo. En este sentido Lathrop señala que: "Es opinión prácticamente unánime que, con el abandono de la casa familiar, el progenitor no cuidador comienza a alejarse del mundo cotidiano del hijo". LATHROP (2011c), p. 95.

${ }^{8}$ Naturalmente que un régimen de custodia compartida supletorio es más garantista que uno de responsabilidad compartida, por cuanto el primero exige una participación equilibrada de ambos padres -no sólo en las decisiones importantes-, sino que también exige una participación equitativa en lo cotidiano. No es que lo cotidiano no esté presente en la responsabilidad compartida, pero es de menor entidad que en la custodia compartida. 
someramente la distinta terminología en algunos Derechos a través de la cual se hace que ambos padres participen en las decisiones importantes de los hijos, y en lo cotidiano, ya sea como régimen general, o de una forma más o menos progresiva ${ }^{9}$; pero antes se hará una breve referencia a la regla de la preferencia materna.

Aparte de los sistemas jurídicos que se basaban en la regla de la superioridad materna, hay otros que a pesar de asignar facultades y derechos de filiación al padre no custodio, conforme al interés superior del niño, eventualmente transgreden dicho principio. Ello se debe a que establecen derechos de filiación desnudos para el padre no custodio.

\subsection{La regla de la preferencia materna como forma de transgresión del interés superior del niño}

En España Picontó señala que, respecto del tema de la edad de los hijos y la preferencia de la madre: "... hasta la reforma legal de 1981 todos los hijos quedaban bajo la guarda del cónyuge de buena fe o "inocente" -no culpable- de la separación (antiguo artículo 73 Cód. Civil). Si ambos padres habían actuado de buena fe o eran "inocentes", los hijos quedaban a cargo del padre y las hijas de la madre (arts. 70 y 73 Código Civil). Y en cualquier caso, los hijos menores de 7 años quedaban al cuidado de la madre, salvo que el juez decidiera de otro modo por motivos especiales"10. Posteriormente, la Ley № 11/1990 modificaría el exartículo 159 del CCE por considerarlo discriminatorio ${ }^{11}$.

En Argentina se aplicaba la regla de la preferencia materna, conforme al exartículo 213 del CC, por el cual los menores de 5 años quedaban siempre a cargo de

\footnotetext{
${ }^{9}$ El presente trabajo se detiene en el sistema español dada su similitud con el sistema chileno, por cuanto en ambos se atribuye el cuidado personal (Chile) o la guarda y custodia (España) por regla general de forma indistinta, y ambos ordenamientos jurídicos establecen mecanismos que permiten que el padre no custodio tenga un rol activo y equitativo en la crianza y educación de los hijos.

10 Picontó (2012), p. 59.

${ }^{11}$ El antiguo artículo 159 del CCE contemplaba una atribución directa del cuidado de los hijos menores de siete años a la madre, salvo que el juez por motivos especiales estableciera lo contrario. Naturalmente que a la vuelta de la democracia en España se discutió su constitucionalidad. A favor de la constitucionalidad de dicha disposición se indicaba que su objetivo era no separar a la madre de los hijos en la etapa de lactancia, y no era fijar directamente un criterio de asignación de la guarda y custodia. Lathrop señala que en la Ley № 11/1990, en la redacción que le dio al artículo 159 del CCE, entregó la decisión sobre el cuidado de los hijos al juez, sin supeditarla a la edad de los niños, tras oírlos, si tienen suficiente juicio, y, en todo, caso si fuesen mayores de doce años. La autora agrega que esta Reforma no introduce ninguna originalidad a la forma de asignación del ejercicio de la patria potestad, por cuanto "conforme al actual párrafo cuarto del art. 92 del CC, los padres pueden acordar en el convenio regulador o el juez decidir, en beneficio de los hijos, que la patria potestad sea ejercida total o parcialmente por uno de los cónyuges". Lathrop (2008a), p. 96.
} 
la madre. Criterio que fue suprimido por el artículo 76 de la $L M C$ que suprimió el término "siempre" ${ }^{\prime 2}$. La Reforma de la Ley № 17.711 estableció que la preferencia materna quedaba descartada ante "causas graves". La Ley No 23.515 modificó el concepto de "causa grave" por las causas "que afecten el interés del menor". La jurisprudencia y doctrina argentinas se plantearon los límites al ejercicio paterno de los derechos de filiación recurriendo a la noción de abuso del Derecho. Esta noción permitió revisar decisiones de los padres contrarias al interés del menor frente a casos en que un padre exigía el reintegro de una hija para ayudarle en un negocio, o la negativa del padre custodio a que el menor se relacione con sus abuelos ${ }^{13}$. En este sentido es clarificadora la jurisprudencia argentina, que antes de las reformas precedentes, era criticada por la doctrina al atribuir la tenencia de los hijos a la madre; pero al menos se respetaba el interés superior del niño al otorgarle contenido a las facultades y derechos del padre no custodio $^{14}$.

El Código Civil chileno, al tiempo de su promulgación, establecía en el exartículo 223 que a la madre divorciada, haya dado o no motivo al divorcio, toca el cuidar personalmente de los hijos menores de cinco años, sin distinción de sexo, y de las hijas de toda edad ${ }^{15}$. Y agregaba que, sin embargo, no se le confiará el cuidado de los hijos, cuando por su depravación sea de temer que se perviertan, lo que se presumirá, si ha sido el adulterio de la madre lo que ha dado lugar al divorcio $^{16}$. La Ley $N^{\circ} 18.802$ estableció que a la madre le correspondía el cuidado de todos los menores, cualquiera que fuese su sexo, salvo depravación. Estas reglas fueron modificadas levemente, sin un mayor debate, por la $L F$, que derogó la

\footnotetext{
12 Polakiewicz (1998), p. 170.

13 ZanNoni (1989), pp. 693-694.

${ }^{14}$ De esta forma es posible consultar los fallos de la Capel. CC Morón, Sala II, 1/6/82, "E.D.", t. 19, pág. 958, sum. 64 y CNC iv, Sala B, 29/5/84, "L.L.", 1984-D, p. 25. Polakiewicz (1998), p. 175.

15 En España en la atribución de la guarda y custodia se ponderaba la culpabilidad de los cónyuges en la ruptura y la edad y sexo de los hijos. La edad fue un criterio a considerar en la nulidad (exartículo 70 del CCE), que se extendería a la separación, mediante una Ley de 1958. El Código Civil además asignaba el cuidado personal del hijo, recurriendo a criterios como la buena o mala fe -en el evento de la nulidad (exartículo 70 del CCE)- y la culpa, en el caso de la separación matrimonial (antiguo artículo $73.2^{\circ}$ del $C C E$. De este modo, el Código Civil español, influenciado por las Siete Partidas, distinguía en cuanto a la edad y sexo de los hijos y a la mala fe y la culpa de los padres en la nulidad o la separación, respectivamente. LATHROP (2008a), p. 58.

${ }^{16}$ A su vez, las normas que regulaban el cuidado de los hijos han variado modificadas en varias ocasiones desde la promulgación del CCCh. De este modo, bajo la vigencia del CCch, el cuidado de los hijos correspondía a la madre, excepto en lo que respecto a los hijos varones mayores de cinco años que pasaban a estar al cuidado del padre. El fundamento de estas distinciones estaba en que los hijos en su temprana edad requieren del cuidado de la madre. Sin embargo, los hijos varones debían seguir el ejemplo paterno. Las Leyes № 5.680/35 y № 10.271/52 siguieron el mismo criterio del CC, pero aumentaron la edad del hijo varón para estar al cuidado paterno, la primera a diez años y la segunda a catorce años.
} 
exigencia de depravación de la madre, e hizo una extraña mezcla entre causales de inhabilidad moral y de interés superior del niño ${ }^{17}$. La $L F$, reguló el exartículo $225.1^{\circ}$ del CC, estableciendo la denominada regla de preferencia materna, señalando una asignación legal supletoria a favor de la madre, en los siguientes términos: "si los padres viven separados, a la madre toca el cuidado personal de los hijos". No contento con ello también estableció una regla de atribución judicial calificada, en el inciso $3^{\circ}$ de la misma norma, que otorgaba el cuidado personal por resolución judicial al padre, pero sólo: "cuando el interés del hijo lo haga indispensable, sea por maltrato, descuido u otra causa calificada". En Chile estos intentos de mimetización llegaron a tal extremo que se planteó el principio de la superioridad materna, como una expresión del interés superior del niño ${ }^{18}$.

La interpretación de tribunales, hasta una importante jurisprudencia del año 2010 de la CS, potenció aún más la referida regla. Los tribunales resolvieron que las únicas causas calificadas para conceder el cuidado personal al padre eran las establecidas en los casos de inhabilidad de la madre (exartículo 226 del CCch y actual 42 de la LPM). De esta forma se aplicaba el exartículo 225 en concomitancia con el exartículo 226 del CCch. En definitiva, la custodia del padre se hacía imposible y sólo operaba en casos de maltrato físico, violación a los hijos, etc. de parte de la madre. Esta interpretación fue desechada por nuestra $C S$, estableciendo que el cuidado personal se debía asignar al padre conforme al principio del interés superior del niño ${ }^{19}$. Así, la CS resolvió que los antiguos artículos $225.3^{\circ}$ y 226 del CCCh tenían un ámbito de aplicación diferente. Los fallos precedentes determinaron el alcance de la expresión "otra causa calificada", a que recurría el antiguo artículo $225.3^{\circ}$ del CCch. En con-

\footnotetext{
17 Esta regla, denominada como preferencia materna, se intentó modificar en el Congreso en la discusión de la $L F$, lamentablemente sin ningún éxito. LATHROP (2010b), p. 151.

${ }^{18}$ Sara Rodríguez se inclinaba, antes de la declaración de inaplicabilidad por inconstitucionalidad de la regla del exartículo $225.3^{\circ}$ y de la derogación del exartículo $225.1^{\circ}$ y $3^{\circ}$, por la constitucionalidad de asignación supletoria legal y judicial calificada a la madre. En lo que toca a su constitucionalidad, la referida autora señala que: "recapitulando, entonces, puede afirmarse que las objeciones de constitucionalidad de la preferencia materna no pueden apoyarse en la regla constitucional que prohíbe diferencias arbitrarias: es una regla supletoria de la voluntad de los padres que no confiere a la madre derecho subjetivo alguno, sino una función o un deber de los que no está privado el padre y que no impide la modificación judicial de la atribución legal en función del interés del niño. La preferencia materna tampoco ofende el interés del hijo. Al contrario, evita litigios y la excesiva judicialización de los conflictos de los padres sobre el cuidado personal de sus hijos y favorece los acuerdos. Todo lo cual no quiere decir que esta regla no admita otras formulaciones, como las que existieron en el Derecho chileno hasta la reforma de la Ley No 18.802 de 1989". Rodrícuez (2009), p. 564.

${ }^{19}$ Ver fallos de la CS (de fecha 24 de junio del 2010 y 16 de agosto del 2010, respectivamente, y corresponden a los autos roles $N^{\circ} 608-2010$ y 4.372-2010) que acogen recursos de casación en el fondo contra sentencias pronunciadas por las CA de Santiago y Antofagasta, respectivamente.
} 
formidad a dicha expresión, la asignación del cuidado personal al padre debía hacerse exclusivamente de acuerdo al interés superior del niño. Sin embargo, al revisar la jurisprudencia, las Cortes asignaban el cuidado personal al padre en consideración al principio del interés superior del niño, en su función de protección de la infancia y no de desarrollo de derechos ${ }^{20}$. De este modo, los tribunales se centraban en una inhabilidad de la madre, de menor rango que la establecida en el antiguo artículo 226 del CCch y el artículo 42 de la $L P M$; pero no consideraban que era lo mejor para el niño, en razón de su desarrollo ${ }^{21}$. En otras palabras sólo se tenía una noción garantista de los derechos de la infancia, que no se centraba en el desarrollo de dichos derechos.

En este escenario se presentó un $P L$ de cuidado personal compartido, que en definitiva dio lugar a la Reforma de $2013^{22}$, y que estableció la actual regulación

${ }^{20}$ Para Gregorio Delgado, aceptar que la madre es la más idónea -con relación al padre- se torna en un principio doctrinario del feminismo de género, sin bases científicas que documenten una aptitud específica de la mujer relacionada con la función que está llamada a desarrollar en los primeros meses y años del hijo; y agrega que si se formulan fundamentos científicos es sólo porque sirven en la lucha de género, permitiéndole a la mujer una ventaja económica frente al padre al momento de organizar la ruptura. No obstante, no niega la importancia de la madre en los primeros años de vida del hijo, pero tampoco desconoce la necesaria presencia del padre. En su versión más jurídica, Carlos Villagrasa señala que el feminismo sostiene que la custodia compartida oculta cuestiones económicas y patrimoniales relacionadas con la vivienda familiar y la pensión alimenticia, y que en realidad no tiene sustento en la pretendida cooperación entre hombres y mujeres. Finalmente, los hijos siguen al cuidado de las mujeres, lo que incide en incrementar aún más la feminización de la pobreza. DelGado (2010), pp. 43-44 y VilLagrasa (2012), pp. 89-90.

${ }^{21}$ En todo caso esta jurisprudencia fue un avance, por cuanto permitió proteger eficazmente a los niños respecto de las madres que, sin recaer en una causal de inhabilidad, estaban afectando el bienestar de sus hijos.

${ }^{22}$ El TC, mediante sentencia de veinte de noviembre de dos mil doce, declaró constitucional la regla del exartículo $225.3^{\circ}$ del CCch; pero a lo menos se contó con los votos de minoría por una parte por el ministro Raúl Bertelsen y, por la otra, por los ministros Marcelo Venegas y José Antonio Viera Gallo. El primero de los votos disidentes señaló, en el considerando $3^{\circ}$, que la regla de atribución del cuidado personal al padre contenida en el artículo $225.3^{\circ}$ del $C C$ ch "resulta excesivamente onerosa y desproporcionada pues exige la ocurrencia de circunstancias tan altas y calificadas que constituyen una diferencia de trato que cabe calificar de arbitraria y que no tiene amparo en la Constitución"; agregando que la referencia a que la asignación al padre sea indispensable para el interés del hijo, pero en atención al únicamente por maltrato, descuido u otra causa calificada "impide al juez, si no concurren estas circunstancias, confiar al padre el cuidado de los hijos aunque fuere simplemente beneficioso de acuerdo a las circunstancias del caso" para, finalmente, en el considerando $4^{\circ}$, resolver que "tal diferencia de trato entre el padre y la madre, excede lo que es lícito hacer al legislador conforme a la garantía constitucional de igualdad ante la ley, puesto que no puede calificarse de razonable o justificada, máxime si la Carta Fundamental, específicamente señala que $<<$ hombres y mujeres son iguales ante la ley $>>$, por todo lo cual debiera declararse la inaplicabilidad de la norma impugnada". El segundo voto disidente, de los ministros Marcelo Venegas y José Antonio Viera Gallo, en su considerando $12^{\circ}$ falla que "esta regla de atribución judicial del cuidado de los hijos de padres separados, aunque declara velar por el interés del niño, en la práctica exige para su aplicación atender a consideraciones de otra naturaleza: Primero, a una virtual 
y expulsó vía ley a la regla de la preferencia materna ${ }^{23}$. Nótese que, antes de esta regulación, la regla de la preferencia materna contenida en el exartículo $225.1^{\circ}$ había sido confirmada como constitucional ${ }^{24}$.

inhabilitación moral del padre o madre que perderá el cuidado, pues habrá de acreditarse que hubo, de su parte, maltrato, descuido u otra causa calificada que haga indispensable la separación de su hijo. Y luego, escrutar si el padre o madre que ahora puede ofrecer buen trato y cuidado al niño en peligro, contribuyó o no a la mantención del hijo mientras estuvo al cuidado del otro padre, pudiendo hacerlo", y agrega, en el considerando $13^{\circ}$, que "no sólo es inconstitucional, sino que resulta contraria al sentido común una regla que, supuestamente concebida para proteger el interés del niño, lleva, en la práctica, al extremo de obligar a un padre a invocar la inhabilidad moral de la madre de su hijo, como único motivo plausible para obtener la custodia del niño, cuando cree que estará mejor a su cuidado (...) Una regla que lleva a este extremo no sólo es contraria a la igualdad sino que atenta contra la dignidad humana y, por cierto, en contra del interés superior del niño". Como sustento del precedente voto de minoría se citan los artículos $3.1^{\circ}, 9^{\circ}$ y 12 de la $C D N, 16$ de la $L T F$ e incluso sentencias del propio $T C$ chileno, referente al interés superior del niño como principio medular del ordenamiento jurídico (roles $\mathrm{N}^{\circ} \mathrm{s} .465$, 786, 1537, 1656 y 1683). Ver: http://www.tribunalconstitucional.cl/wp/ver.php?id=2593.

${ }^{23}$ A este respecto es conveniente traer a colación las palabras de Delgado, que señala: "... no me resisto a transcribir una valoración -que comparto- de la Juez María Sanahuja. Dice así: <<si queremos superar el modelo de la caverna -él caza, ella se ocupa de la prole- crecer profesionalmente y enriquecer a nuestros hijos, la custodia compartida tiene que ser nuestro modelo >>". Delgado (2010), p. 205.

${ }^{24}$ La sentencia del TC, de 30 de mayo del 2013, rol № 2306-12-INA, acogió parcialmente un requerimiento de inaplicabilidad por inconstitucionalidad presentado por Luis Palma Bustamante respecto del exartículo $225.1^{\circ}$ (asignación legal supletoria a la madre) y $3^{\circ}$ (asignación calificada al padre) del Código Civil, en los autos sobre alimentos de que conoció el Segundo JF de San Miguel, bajo el RIT N C-1303-2012, RUC 12-2-0181864-6. Y, a este respecto, resolvió: "que se acoge parcialmente el requerimiento de inaplicabilidad deducido a fojas 1 , solo en cuanto se declara la inaplicabilidad de la frase que $<<$ cuando el interés del hijo lo haga indispensable, sea por maltrato, descuido u otra causa calificada", contenida en el artículo 225 del Código Civil >>". Los incisos precedentes eran del siguiente tenor: "Artículo 225.- Si los padres viven separados, a la madre toca el cuidado personal de los hijos" (inciso $1^{\circ}$ ) y "en todo caso, cuando el interés del hijo lo haga indispensable, sea por maltrato, descuido u otra causa calificada, el juez podrá entregar su cuidado personal al otro de los padres. Pero no podrá confiar el cuidado personal al padre o madre que no hubiese contribuido a la mantención del hijo mientras estuvo bajo el cuidado del otro padre, pudiendo hacerlo" (inciso $3^{\circ}$ ).

Esta sentencia acoge el requerimiento parcialmente fundado en la garantía de igualdad ante la ley (los fundamentos del recurso son los artículos 12, 14, 16 y 18 de la CDN). Los argumentos con que la madre demandada de cuidado personal evacúa el traslado son absolutamente claros a este respecto. En este sentido, la recurrida se defiende alegando que: "...en el mundo animal es la hembra la que cría y alimenta, que el cuidado personal para la madre no es un privilegio ni un acto discriminatorio", y agrega el $T C$, respecto de la defensa de la madre, que: "a continuación se refiere a la igualdad ante la ley, señalando que tiene elementos formales y materiales, debiendo tratarse diferente a los desiguales, en el marco del principio de proporcionalidad, por lo que las excepciones a reglas generales no son per se un atentado a la igualdad, ya que hipótesis de hecho diferentes se tratan de manera diferente". EI TC desechó la inaplicabilidad respecto del ex art. $225.1^{\circ}$, por dos razones. La primera es que en concreto el cuidado personal se radicó en la madre por acuerdo de los padres, y no por aplicación de la referida norma. La segunda, se refiere al fondo y se inclina por la constitucionalidad del referido inciso, resolviendo que: “...así, cabe concluir que: la regla de atribución preferente a la madre del cuidado personal de los hijos no representa, por sí misma, una vulneración a la garantía de igualdad ante la ley, pues aunque introduzca una diferencia de trato entre la madre y el padre, la misma tiene 


\subsection{La asignación de facultades y derechos de filiación a uno de los padres conforme al principio del interés superior del niño, pero que sin embargo trasgreden la referida máxima}

Un régimen de asignación indistinto de facultades y derechos de filiación, incluso conforme al interés superior, puede ser tan discriminatorio y transgresor del interés superior del niño, como la regla de la preferencia materna, en la medida que las facultades y derechos de filiación se concentren exclusivamente en el padre custodio. Se ha sostenido que la atribución unipersonal del cuidado personal, a uno de los padres, implica conferirle una cuota de poder, en lo relacionado con la parentalidad, que representa una compensación a la cuota de poder económico que conserva generalmente aquel de los padres, que no convive con los hijos. Y ello acontece aun en un régimen de facultades y derechos para el padre no custodio. Así, Polakiewicz señala que la compensación aparente, a favor del padre no custodio, termina por generar una sobrecarga en las responsabilidades que se derivan de los poderes asignados a cada uno de los padres y conduce a una paulatina desvinculación en las funciones atribuidas al otro miembro de la pareja parental ${ }^{25}$. Esta es una fuerte crítica a los sistemas que no establecen formas de cuidado compartido como régimen supletorio y preferente. En contra de esta posición nuestro $T C$ comprende que en la medida en que la $R D R$ cumpla con

\footnotetext{
justificación en la realidad social de nuestro país. De ahí que la adopción de esta regla por el legislador es una opción lícita, que, además, por su fácil aplicación, simplifica la solución de un problema que muchas veces requiere de una definición urgente para no lesionar el interés superior de los niños. Por lo demás, no se trata de una regla absoluta, desde el momento que ella puede ser alterada por acuerdo de los padres, como también por resolución judicial dictada conforme al inciso tercero del artículo en cuestión, lo que se analizará a continuación" (considerando 15).

El sustento de la inconstitucionalidad del inciso $3^{\circ}$ para el $T C$, se basa en lo siguiente: "que, por lo expuesto, puede apreciarse que la aplicación en el caso que nos ocupa del inciso tercero del artículo 225 del Código Civil, produce una diferencia de trato que excede lo que es lícito hacer al legislador conforme a la garantía constitucional de igualdad ante la ley, la que sólo admite la diferencia que pueda calificarse de razonable o justificada, máxime si la Carta Fundamental, específicamente señala que <<hombres y mujeres son iguales ante la ley $>>$, por todo lo cual debe declararse la inaplicabilidad del inciso tercero del artículo 225 del Código Civil, únicamente respecto de la frase que dice $<<$ cuando el interés del hijo lo haga indispensable, sea por maltrato, descuido u otra causa calificada $>>$ y así se declarará" (considerando vigésimo primero). Para finalizar existen tres votos de minoría. El primero es una prevención, el segundo está por desechar la inconstitucionalidad parcial y el tercero está por declarar también la inconstitucionalidad del inciso $1^{\circ}$ (CARMOna, García y Brahm). Ver: file:///C:/Users/rbarcia/Downloads/2779.pdf.

${ }_{25}$ Gregorio Delgado señala que es contrario al hecho de que sea uno de los progenitores quien ostente la patria potestad -habitualmente la mujer y madre- pues: "origina de hecho la marginación del varón/ padre y perjudica, a la corta y a la larga, a los menores (vacío afectivo)", debiendo ser reservada a ambos progenitores. Delgado (2010), p. 235.
} 
el principio de la corresponsabilidad, el sistema jurídico perfectamente puede excluir el cuidado personal compartido con oposición de un padre ${ }^{26}$.

En síntesis, el progenitor a quien se le ha otorgado el cuidado personal comienza a $<<$ apoderarse $>>$ de los hijos, y el padre no custodio comienza a apartarse del ejercicio cotidiano de la parentalidad y a $<<$ apoderarse $>>$ del control del dinero, restringiendo los aportes necesarios para su manutención ${ }^{27}$. La forma de romper con este círculo vicioso es establecer un régimen que promueva la participación del padre no custodio en la educación y crianza de los hijos, impidiendo fomentar regímenes que en los hechos consagren facultades y derechos de filiación desnudos para el padre no custodio. A lo que se suma el que el padre no custodio, en la medida en que su fuerza patrimonial lo permita, cumpla con su deber de alimentos en el tiempo que el hijo esté con el padre custodio.

La influencia de la asignación de derechos de filiación a favor de uno de los padres, aun inspirando la decisión en el interés superior del niño, determina el comportamiento de ambos padres e impone una relación de poder en la familia ${ }^{28}$. Por ello, los ordenamientos jurídicos, que asignan el cuidado personal a uno de los padres, establecen categorías conceptuales que buscan evitar la consagración de facultades y derechos de filiación desnudos. Ello evita transformar al padre no custodio en un $<<$ visitante $>>$, que no participa en la crianza y educación de sus hijos.

\section{El principio del interés superior del niño como una forma de articular un sistema de custodia conjunta (aplicación del principio de igualdad de los padres): Extensión de la participación progresiva del padre no custodio en la crianza y educación de los hijos (aplicación de la corresponsabilidad)}

No cabe la menor duda de que el principio del interés superior del niño ha sido la piedra angular sobre la cual se ha construido el actual Derecho de la

\footnotetext{
${ }^{26}$ Una sentencia del TC, de 16 de junio del 2015, rol № 2.699-2014, rechazó un recurso de inconstitucionalidad en contra del inciso $3^{\circ}$ del artículo 225 CCCh. Y en torno a lo que nos interesa resolvió que la corresponsabilidad no faculta al juez para decretar el cuidado personal con oposición, por cuanto se trata de instituciones diferentes; y que es la $R D R$ la llamada a hacer efectiva la corresponsabilidad (cons. $6^{\circ}$ y $7^{\circ}$ ).

27 Para Polakiewicz las numerosas demandas por alimentos son prueba suficiente de ello. Polakiewicz (1998), p. 171.

${ }^{28}$ En Argentina Polakiewicz nos señala con claridad, respecto a la regulación que precede al reciente Código Civil Argentino, que: "con independencia de la evaluación de los criterios para la atribución de la tenencia de los hijos, cabe una consideración respecto del significado propio de la atribución de la tenencia a uno de los progenitores, como concesión de una facultad o un poder a uno de ellos en detrimento del otro. La influencia de esta decisión judicial, aun antes de que ésta se produzca, es determinante de la organización de las relaciones de poder en la familia, sobre todo en la pareja parental. POLAKIEWICZ (1998), p. 171.
} 
Infancia ${ }^{29}$; pero en la actualidad no cabe sino entenderlo dentro de un sistema de derechos fundamentales ${ }^{30}$, íntimamente vinculado al principio de la igualdad de los padres ${ }^{31}$.

Una de las tesis que ha sido corregida fuertemente por la Ley $N^{0} 20.680, y$ con menor fuerza por tribunales, es la que asimila el interés superior del niño al interés de la madre.

El interés superior del niño se aplica fundamentalmente en los siguientes tres ámbitos: (a) como un principio de protección de la infancia, en cuyo caso se centra en niños vulnerables, VIF, adolescentes que quieran tomar decisiones que afecten su vida futura, etc.; (b) como un principio autonomía progresiva, que otorga capacidad a los menores -principalmente respecto de los adolescentes y excepcionalmente-, que permite ejercer directamente los derechos fundamentales de la infancia y (c) como un principio que delimita las facultades y deberes

${ }^{29}$ Como destaca De la Válgoma, la idea del interés del niño se puede encontrar hacia fines del siglo XVI, pero cobró fuerza en los siglos XVIII y XIX. Dicho principio se consagraría por primera vez en la Guardianship of Infants Act, que hizo del bienestar del niño la primera y suprema consideración, convirtiendo en ley lo que sólo era un compromiso moral de los padres. El principio se universalizó con la Convención de Derechos del Niño. De la Válgoma (2013), p. 73.

${ }^{30}$ Roca defiende la teoría de que la determinación del interés del menor estaría en la defensa de los derechos fundamentales. La referida autora señala que todo el derecho de familia tiene esa eficacia, $y$, por tanto, promueve los derechos fundamentales de los miembros del grupo familiar, no los de la familia como tal. De la Válgoma, citando a Roca Trías, sostiene que el interés del menor se reconoce a través de dos sistemas: identificándolo en situaciones incluidas en el concepto general y que proporciona al juez una guía al tomar decisiones que afectan al menor, o introduciendo una cláusula general en la que sólo se impone la necesidad de actuar en interés del menor, sin darle un contenido concreto. Este último sistema es el elegido por prácticamente todo el derecho continental. De LA VÁLGOMA (2013), p. 81. Igual fenómeno es percibido en Argentina. Así, para Herrera, el final del siglo pasado se caracteriza por la democratización de las relaciones de familia y la autonomía de los miembros de la familia. HeRrera (2015), p. 597.

31 Los tribunales no deben hacer una aplicación descontextualizada del principio del interés superior con relación a otros derechos fundamentales. En este sentido es conveniente recordar el reproche que le hizo a Chile la CIADH, en el fallo de fecha 24 de febrero de 2012, autos "Atala Riffo y niñas vs. Chile". La crítica fundamental de la sentencia de la CIADH fue que, aunque el interés concreto de las niñas sea evitarles el sufrimiento de la discriminación porque su madre tenía una pareja del mismo sexo, no se puede soslayar que dicha forma de entender el interés superior del niño era discriminatoria por razones de sexo. La CIADH, en su considerando $121^{\circ}$, resuelve que: "...en cuanto al argumento de que el principio del interés superior del niño puede verse afectado por el riesgo de un rechazo por la sociedad, la Corte considera que un posible estigma social debido a la orientación sexual de la madre o el padre no puede considerarse un $<<$ daño $>>$ válido a los efectos de la determinación del interés superior del niño. Si los jueces que analizan casos como el presente constatan la existencia de discriminación social es totalmente inadmisible legitimar esa discriminación con el argumento de proteger el interés superior del menor de edad. En el presente caso, el Tribunal resalta que, además, la señora Atala no tenía por qué sufrir las consecuencias de que en su comunidad presuntamente las niñas podrían haber sido discriminadas debido a su orientación sexual". Ver: http://www.corteidh.or.cr/ docs/casos/articulos/seriec_239_esp.pdf (consultado el 9 de mayo de 2012). 
de los padres con relación a los hijos. Naturalmente que es ésta la vertiente en que se analiza el principio del interés superior en el presente trabajo, por cuanto plantea la necesidad de construir facultades y deberes del padre no custodio.

La Reforma de 2013 reformó la forma de asignar el cuidado personal respecto de los padres que estén separados y en caso que no haya mediado acuerdo entre ellos. Al respecto se estableció en el artículo $225.4^{\circ}$ a $6^{\circ}$ del CCch, que: [e]n cualesquier de los casos establecidos en este artículo, cuando las circunstancias lo requieran y el interés superior del hijo lo haga conveniente, el juez podrá atribuir el cuidado personal del hijo al otro de los padres, o radicarlo en uno solo de ellos, si por acuerdo existiere alguna forma de ejercicio compartido.

Lo anterior debe entenderse sin perjuicio de lo dispuesto en el artículo 226.

En ningún caso el juez podrá fundar exclusivamente su decisión en la capacidad económica de los padres.

Siempre que el juez atribuya el cuidado personal del hijo a uno de los padres, deberá establecer, de oficio o a petición de parte, en la misma resolución, la frecuencia y libertad con que el otro padre o madre que no tiene el cuidado personal mantendrá una relación directa y regular con los hijos, considerando su interés superior, siempre que se cumplan los criterios dispuestos en el artículo $229^{\prime \prime}$. A su vez, los artículos $234.2^{\circ}$ y $242.2^{\circ}$ del CCch contemplan un deber de resguardo para el juez, oponible a cualquiera que pudiere o menoscabare al menor. El criterio fundamental para la asignación del cuidado personal y la consagración de las facultades y derechos del padre no custodio será el bienestar del hijo, conforme al cual los padres podrán solicitar al juez que determine lo más conveniente para su vida futura. Este principio también se consagra en los artículos $3.1^{\circ}, 27.2^{\circ}, 54.1^{\circ}, \mathrm{N}^{\circ} 5$ y 6, y $85.2^{\circ}$ de la $L M C$ y 105 , letra e) de la $L T F$.

La doctrina ha señalado que el interés superior del niño es una expresión superlativa, que hace que este interés deba ser preferido sobre otras consideraciones, sobre todo en lo que se refiere a los derechos fundamentales de la infancia ${ }^{32}$. Sin embargo, como los derechos fundamentales deben ser ponderados respecto de otros derechos fundamentales, en los casos en que se produce un conflicto, la máxima precedente es sólo una regla general.

En Argentina, antes de la promulgación del $C C$ y $C$, la titularidad de la patria potestad correspondía a ambos padres, aun cuando estén separados, y la tenencia, se asignaba a uno de los padres (exartículo $264.2^{\circ}$ e $5^{\circ} \mathrm{CCiv}$ ). Al otro

\footnotetext{
32 Así se puede consultar a Javier Barrientos, que señala que los derechos fundamentales del niño deben prevalecer sobre cualquier otra consideración. Para el referido autor, siguiendo a Peña, el interés superior -al que hace referencia nuestra legislación- se centra en "el respeto de los derechos fundamentales de los niños, con la limitación de su <<estado de maduración >>, por sobre cualquier otro <<interés >>". BarRientos (2011), pp. 115 y 116.
} 
progenitor le correspondía un derecho de comunicación con el niño o adolescente y de supervisión (exartículo 264.2 , CCiv). Nuevamente, se apreciaba en la legislación argentina una tendencia a respetar los derechos de la infancia al otorgar facultades y derechos al padre no custodio. Sin embargo, estos derechos y facultades fueron más bien limitados y han sido objeto de crítica por parte de la doctrina trasandina ${ }^{33}$. Precisamente estas críticas han llevado a que la nueva legislación distinga entre titularidad y ejercicio de la responsabilidad parental (artículo 640 CC y C) ${ }^{34}$, y responsabilidad parental conjunta, aun en caso que los padres estén separados (artículo 641.b) CC y C) ${ }^{35}$.Sin perjuicio de lo anterior, el gran principio inspirador del $C C$ y $C$ es la coparentalidad, y especialmente

\footnotetext{
${ }^{33}$ En este sentido se puede consultar a Cataldi: "se infiere implícitamente de este texto un resultado poco razonable: uno tiene el derecho-deber de educar al hijo y el padre no guardador sólo puede vigilar desde afuera el modo en que es ejercido, como si fuera un extraño. Esta comprensión contradice la idea de participación y colaboración e implica para el hijo una pérdida que vulnera su derecho a ser cuidado y educado por ambos padres (arts. $7^{\circ}$ y 18 de la $C D N$ ). De ordinario, es la madre la que toma a su cargo el cuidado del hijo, pues a ella se le adjudica, generalmente, la guarda de los hijos, ya sea por acuerdo de los padres o por decisión judicial. El sistema legal argentino, que otorga el ejercicio de la responsabilidad parental sólo al padre a quien se le ha conferido $<<$ la tenencia $>>$, ha sido juzgado por una gran parte de la doctrina nacional como contrario a la igualdad de derechos y la adecuada equivalencia de responsabilidades de los progenitores en la crianza y educación de los hijos asegurado en diversos tratados de derechos humanos, que en nuestro país tienen rango constitucional (en especial, la Convención sobre Eliminación de Todas las Formas de Discriminación contra la Mujer, arts. 5.b y 16.d y CDN, art. 18.1)". CATALDI (2015), p. 3.
}

34 Medina (2014), p. 2 y CaIIGAL (2016), p. 291.

Las normas que regulan esta figura en caso de desacuerdo entre los padres son las siguientes:

"rt. 640 [Figuras legales derivadas de la responsabilidad parental].

Este Código regula: a) la titularidad y el ejercicio de la responsabilidad parental (...)".

"art. 641 [Ejercicio de la responsabilidad parental].

El ejercicio de la responsabilidad parental corresponde: (...)

b) en caso de cese de la convivencia, divorcio o nulidad de matrimonio, a ambos progenitores. Se presume que los actos realizados por uno cuentan con la conformidad del otro, con las excepciones del inciso anterior. Por voluntad de los progenitores o por decisión judicial, en interés del hijo, el ejercicio se puede atribuir a sólo uno de ellos, o establecerse distintas modalidades (...)".

“art. 642. [Desacuerdo].

En caso de desacuerdo entre los progenitores, cualquiera de ellos puede acudir al juez competente, quien debe resolver por el procedimiento más breve previsto por la ley local, previa audiencia de los progenitores con intervención del Ministerio Público.

Si los desacuerdos son reiterados o concurre cualquier otra causa que entorpece gravemente el ejercicio de la responsabilidad parental, el juez puede atribuirlo total o parcialmente a uno de los progenitores, o distribuir entre ellos sus funciones, por un plazo que no puede exceder de dos años. El juez también puede ordenar medidas de intervención interdisciplinaria y someter las discrepancias a mediación". Ver: http://www.scba.gov.ar/leyorganica/CCyc30/CODIGO30.html\#_RefHeading_31482_628858921.

35 Notrica y Rodríguez, señalan, respecto de la referida Reforma, que: "... la reforma propuesta adaptó la institución a las exigencias sociales y a la tendencia dominante en el derecho comparado, al remplazarse el sistema vertical creado por el codificador, por un sistema que plantea, en términos horizontales, la relación entre todos los miembros de la familia, fundado en principios de libertad, 
el cuidado compartido, que permitiría regular diversos tipos de familia, como los casos de las familias ensambladas. El CC y $C$, reguló en el Libro II, Título VII, Capítulo 7, denominado "Deberes y derechos de los progenitores e hijos afines" (artículos 672-676), la figura de los progenitores afines ${ }^{36}$.

En España, aun en caso de que los padres estén separados, la titularidad de la patria potestad mantiene las facultades/deberes de velar y alimentar a los hijos ambos padres. Así se establece por mandato del art. 154 del CCE reforzado por el art. $39.3^{\circ}$ de la CPE. Por lo que, incluso en los casos excepcionales en que los padres no tienen el ejercicio conjunto de la patria potestad, el padre no custodio conserva el derecho de vigilancia o control. No hay consenso respecto de los alcances de este deber/facultad. Así, para Rabadán consistiría en "que la labor de cuidado desempeñada por el guardador no sea perjudicial para los hijos". Y, agrega el autor precedente que en caso de que el padre pierda la titularidad de la patria potestad, cesará el derecho de vigilancia (artículos 110 y 111 del $C(E)$, pero no el de asistencia que se debe al guardador con miras al beneficio de los hijos. La titularidad implica la intervención del padre respecto de la emancipación, adopción o matrimonio del menor ${ }^{37}$. Así, tanto en

igualdad y solidaridad, afianzando la $<<$ democratización de las relaciones de familia $>>$, siendo esencialmente la que involucra el lazo entre padres e hijos".

Notrica y RodríGuez (2014), p. 3.

${ }^{36}$ Así, el CC y C aplica la coparentalidad más allá de la filiación, como se desprende de la definición que preceptúa la legislación de esta figura. El artículo 672, del referido cuerpo normativo, define al progenitor afín como "al cónyuge o conviviente que vive con quien tiene a su cargo el cuidado personal del niño o adolescente". Y regula los deberes de los progenitores afines en los siguientes términos:

"art. $673.1^{\circ}$ [Deberes del progenitor afín]. El cónyuge o conviviente de un progenitor debe cooperar en la crianza y educación de los hijos del otro, realizar los actos cotidianos relativos a su formación en el ámbito doméstico y adoptar decisiones ante situaciones de urgencia. En caso de desacuerdo entre el progenitor y su cónyuge o conviviente prevalece el criterio del progenitor".

Incluso el padre custodio, subsidiariamente puede delegar en el progenitor afín el ejercicio de la responsabilidad parental, conforme al artículo 674; también se pueden celebrar acuerdos de custodia conjunta, en caso de fallecimiento del otro padre, con homologación judicial, de acuerdo al artículo 675 , y se consagra un deber de alimentos subsidiario que recae sobre el progenitor afín, que puede excepcionalmente subsistir a la ruptura del vínculo con el progenitor (artículo 676, todos del CC y C). A su vez, respecto de la coparentalidad, Martín señala que: "El Código Civil y Comercial aporta varias respuestas jurídicas útiles, pero no debe suponerse que son lo suficientemente dúctiles para abarcar a todo el catálogo de supuestos susceptibles de presentarse en materia de función parental en la familia ensamblada. Cuando imaginamos los diferentes grados de participación del padre o madre afín en el ejercicio de la parentalidad del hijo de su pareja, así como determinadas trayectorias que quizás aparezcan en el ciclo vital del grupo, surgen combinaciones familiares -incluso frecuentes - que no han sido aprehendidas (era imposible que lo sean) en la novel normativa en toda su dimensión, requiriéndose que los jueces realicen ciertos ajustes por vía interpretativa para brindar una solución acorde a las circunstancias que se presenten con un determinado núcleo familiar ensamblado".

MARTín (2015), pp. 5-6.

37 RABADÁN (2011), pp. 26-27. 
Argentina como España, el padre no custodio tiene un mínimo de derechos y facultades que tienen su sustento en la ley, pero luego este mínimo se extiende vía jurisprudencia.

Una de las manifestaciones más importantes del principio de igualdad de los padres, es que ambos progenitores cuentan con la facultad-deber para asumir la custodia de sus hijos, ya que ninguno de los progenitores cuenta con un derecho preferente. La forma en que se relaciona este principio con el interés superior del niño no es baladí. En España para algunos autores, como García, la igualdad de los padres cede en la función de guarda y custodia, ante el principio $<<$ favor filii $>\rangle^{38}$. En realidad esta forma de entender el interés superior es limitada y debe revisarse por cuanto el interés superior está tan relacionado con la igualdad de los padres, que sólo en casos extremos ambos principios están en conflicto ${ }^{39}$. La doctrina española relevante es casi unánime a este respecto. El interés superior del niño, en caso de conflicto con otros intereses, no supone una preferencia matemática a favor del interés del hijo sobre el interés de los padres. El interés de los padres debe ser tomado en consideración ${ }^{40}$, al estar integrado en el interés de los hijos ${ }^{41}$.

\footnotetext{
38 García (2013), p. 116.

39 Por señalar algunos ejemplos, en el Estado de Maine las formas de custodia conjunta son las supletorias y el juez puede conceder la custodia indistinta, pero dando las razones para negar la coparticipación de los derechos y responsabilidad parentales. La Maine Revised Statutes Annotated, title 19-A; Domestic Relations $\S 1653$, sub-\$1.a, dispone: "2. Parental rights and responsibilities; order. This subsection governs parental rights and responsibilities and court orders for parental rights and responsibilities)". En Italia, por aplicación del artículo 155 del Codice, ocurre otro tanto.
}

${ }^{40}$ Delgado, respecto de la interacción de los principios de igualdad de los padres e interés superior, señala que: "... la presencia de las dos figuras parentales es prioritaria para los menores en cualquier tipo de guarda que se arbitre. No sólo en los supuestos de custodia compartida... La necesaria referencia a ambos padres, la efectiva contribución de ambos progenitores -rasgo vital de la vida humana- la participación y colaboración activa de ambos padres sigue siendo una de las asignaturas pendientes en torno al tema. (...) no existe en nuestro ordenamiento jurídico una suerte de presunción de idoneidad -en cuanto a la guarda y custodia de los hijos- que juegue a favor de alguno de los progenitores...". Delgado (2010), p. 247.

${ }^{41}$ Así, lo han entendido Cruz, Delgado y Rabadán, entre otros. Cruz señala que el interés del menor "debe por tanto coordinarse con los demás intereses del grupo donde se inserte, por lo que no siempre en términos absolutos podrá tener un valor prioritario". El interés del niño, como interés primordial, juega sobre todo en los casos de peligro para el niño o en los casos que debamos aplicar el principio del interés superior como principio de protección de los derechos de la infancia. Un arrinconamiento de los demás derechos de los padres naturalmente que va en perjuicio del niño. Esta tendencia, como señala Cruz, también es reconocida por la sentencia del TCE, № 176/2008, de 22 de diciembre, que resuelve: "...el criterio que ha de presidir la decisión que en cada caso corresponde adoptar al juez, a la vista de las circunstancias concretas, debe ser necesariamente el del interés prevalente del menor, ponderándolo con el de sus progenitores, que aun siendo de menor rango, no por ello resulta desdeñable". Y Delgado, a este respecto, es aún más tajante cuando se pregunta: "desde la perspectiva 
La importancia del principio de igualdad, como máxima orientadora del interés superior del niño, ya lo ponía de manifiesto el Reglamento (CE) núm. 2201/2003 de Consejo, de 27 de noviembre del 2003, relativo a la competencia, el reconocimiento y la ejecución de resoluciones judiciales en materia matrimonial y de responsabilidad parental. Dicha reglamentación estableció que las medidas judiciales adoptadas en materia civil -especialmente las medidas tendientes a garantizar la igualdad de los menores en cuanto a la responsabilidad parental- tendrán fuerza ejecutiva. En igual sentido para Herring, Probert y Gilmore, el aspecto más relevante de la Reforma a la $\langle<$ ChildrenAct $>>$ de 1989 , en el $R U$ consistió en que, cualquiera que sea el régimen que establezca la Corte, el contacto entre padres e hijos es la manifestación del interés superior del niño ${ }^{42}$. El juez sólo en casos excepcionales puede modificar esta regla ${ }^{43}$.

del interés/beneficio de los hijos, se impone (...) una pregunta, que ya formulamos en otro momento. Es ésta: ¿es entendible un desarrollo armónico y equilibrado del proceso de maduración personal de los hijos sin una permanente referencia a ambos progenitores? La respuesta, a mi entender, ha de ser, en principio, negativa. Y ello con independencia del sistema de guarda que se establezca e incluso en el ámbito de una convivencia conyugal normal.

El interés del menor responde a situaciones más complejas que las habituales. Su tutela sólo se satisface de modo eficaz en casos excepcionales cumplidamente acreditados, mediante una guarda atribuida exclusivamente a uno de los padres. En principio, el contacto regular y fluido con ambos padres parece más viable y eficaz en el desarrollo equilibrado y armónico de los hijos.

Finalmente, Rabadán señala que, en los casos de desavenencia en torno a aspectos fundamentales de la infancia con relación al enfrentamiento entre padres e hijos, no se debe recurrir el juez, sino dejar a la solución en el seno de la familia, o recurrir a una mediación. La intervención judicial sería el último recurso. Cruz (2012), p. 179; Delgado (2010), p. 213 y Rabadán (2011), p. 38. En el mismo sentido anterior se puede consultar a LINACERO (2006), p. 64 y RUISÁNCHEZ (2006), p. 30.

${ }^{42}$ En esta parte la referida Ley se hace cargo de varias sentencias ( $R$ vs United Kingsom, $W$ vs UK y $O$ vs UK) del TEDH que condenaban al $R U$ por no establecer mecanismos de ejecución de visitas contra los organismos de seguridad social y respecto de los padres no matrimoniales.

${ }^{43}$ A raíz de las modificaciones a la Children Act 1989, los autores se hacen cargo del debate de variados temas que son resueltos por las Cortes en los siguientes sentidos: "El contacto entre padre e hijo es un elemento fundamental de la vida familiar y es, prácticamente siempre, en el interés del menor; el contacto entre padre e hijo debe terminar sólo en circunstancias excepcionales, en que existen razones convincentes para hacerlo y cuando no hay alternativa. El contacto se debe terminar sólo si es perjudicial para el bienestar del menor; existe una obligación positiva del Estado, y por consiguiente del juez, de tomar medidas para mantener y reconstituir la relación entre padre e hijo, en definitiva, para mantener o restablecer el contacto. El juez tiene un deber positivo de procurar promover el contacto. El juez debe lidiar con todas las alternativas disponibles antes de abandonar la esperanza de lograr algún tipo de contacto. El juez debe ser cuidadoso de no llegar a una decisión prematura, el contacto debe detenerse sólo como último recurso y sólo una vez que ha quedado claro que el menor no se beneficiará de continuar con el intento. La Corte debe considerar tanto una visión de mediano como de largo plazo y no otorgar un peso excesivo a lo que probablemente parezca ser un problema transitorio o de corto plazo; la pregunta clave, que debe hacerse el juez es si ha tomado todos los pasos necesarios para facilitar el contacto, como puede ser razonablemente dadas las circunstancias del caso particular, y todo lo anterior constituye el bienestar del menor, que debe verse reflejado en que 
Esta mirada crítica al actuar del Estado con relación al Derecho de la Infancia y a los excesivos poderes que se les otorga a los tribunales y a la Administración es de larga data, ya era manifestada en 1971 y en 1976 en los Estados Unidos de América ${ }^{44}$.

La visión del interés superior del niño, aislada del interés de los padres, ha generado una fuerte crítica a la forma en que la jurisprudencia ha comprendido este principio. Así, en España, De la Válgoma señala que muchos autores se han mostrado críticos, no con el principio del superior interés del niño, sino respecto de la forma en que los jueces lo vienen aplicando. De este modo cita, entre estos autores, en Francia, a Carbonnier y Donnier; en Italia, Dogliotti y en España, a Alonso Pérez, Gullón y Díez-Picazo ${ }^{45}$. Y ello se debe a que el principio apela a una concepción objetiva del interés primordial de la infancia, que se completa conforme a los derechos fundamentales; pero también a una concepción más dúctil (en sentido positivo) o vaga (en sentido negativo), respetuosa de los estándares culturales de cada sociedad. Así, no obstante la universalidad de los derechos fundamentales, éstos deben ser considerados teniendo en cuenta la significación de las particularidades nacionales o locales y sus antecedentes culturales y religiosos ${ }^{46}$. El interés superior del niño no puede ser aplicado de la misma manera, en distintos lugares del mundo, aunque el principio sea el mismo ${ }^{47}$.

A pesar que de lo señalado precedentemente se desprenden dos concepciones del interés superior. Una que atiende a los derechos fundamentales, comprendidos de forma universal y absoluta, y otra que atiende a las particularidades de cada sociedad en la que se aplica el referido principio. En realidad es posible complementar ambas formas de comprender el interés superior con

el interés primordial es 'el interés del menor' que tiene prioridad sobre cualquier otra consideración'". HERRING y otros (2015), pp. 94-95.

${ }^{44}$ A este respecto Foster y Freed recuerdan la opinión que el prof. Sanford N. Katz mantenía en la década de los 70, señalando: "Professor Sanford has pointed out, most effectively, that the greatest intrusion of government into family life has been with reference to the parent-child relationship which most often occurs in the case of the poor". Sin perjuicio de lo anterior, este problema es más o menos reciente, como se desprende de lo señalado por Hafen, para el cual existe una presunción a favor de la decisión de los padres y en contra de la intervención del Estado en los años 70. Así, el referido autor de la opinión que: "a series of Supreme Court opinion has addressed the subject of parental prerogatives in a number of contexts and appears to have established a strong presumption favoring parental control, at least as against intervention from the state". Foster y Freed (1992) (1972), pp. 6 y 346 y HaFEN (1992) (1972), y pp. 619 y 127.

45 De la Válgoma (2013), pp. 137-139.

${ }^{46}$ Alston, Parker, Eekelaar, Freeman, entre otros.

47 De la Válgoma (2013), pp. 143-144. 
relación a los padres. Sin lugar a dudas, el interés superior del niño lo que busca es la mejor forma de desarrollo de los derechos de la infancia en concreto; pero ello no significa que se pueda desconocer que ambos padres tienen un derecho preferente en la determinación de lo que concretamente es mejor para sus hijos, dentro de los parámetros estatutarios que da la sociedad y el Derecho.

Por ello una forma abordar esta tensión es centrarse en los derechos fundamentales de la infancia. En este sentido Greeven, siguiendo a Miguel Cillero, señala que el interés superior del niño es la plena satisfacción de todos sus dere$\operatorname{chos}^{48}$. La correcta aplicación del principio requiere de un análisis conjunto de todos los derechos afectados y de los que se pueden afectar por una resolución judicial. A este respecto, Greeven señala que: "siempre ha de tomarse aquella medida que asegure:

a) La máxima satisfacción de los derechos que sea posible.

b) La menor restricción de ellos.

c) Debiendo considerar el número de derechos afectados y su importancia relativa" ${ }^{49}$.

Nótese que esta forma de entender el interés superior del niño, dentro de un contexto de respeto de los derechos fundamentales y especialmente del derecho de los padres, tiene acogida, en la Observación General № 14 (2013) del Comité de los Derechos del Niño de Naciones Unidas sobre el derecho del niño a que su interés superior sea una consideración primordial (artículo $3^{\circ}$, párrafo 1). La referida Observación indica que el interés superior del niño tiene una triple dimensión: un derecho sustantivo, un principio jurídico interpretativo fundamental y una norma de procedimiento. El Comité de Derechos del Niño establece que para su aplicación al caso concreto se deben seguir dos pasos: a) determinar cuáles son los elementos pertinentes, en el contexto de los hechos concretos del caso, para evaluar el interés superior del niño, dotarlos de un contenido concreto y ponderar su importancia en relación con los demás; b) para ello, seguir un procedimiento que vele por las garantías jurídicas y la aplicación adecuada del derecho ${ }^{50}$. Asimismo se refiere expresamente a los padres separados, agregando que: "el Comité reconoce la necesidad de cierto grado

${ }^{48}$ Greeven (2014), pp. 66-67.

49 Greeven (2014), p. 65.

${ }^{50} \mathrm{El}$ instrumento precedente es importante por cuanto los que le siguieron guardaron relación con la infancia comprendida en sentido asistencial y cultural, como se puede desprender de las Observaciones Generales: № 15 en torno al derecho del niño al disfrute del más alto nivel posible de salud; № 16 : relativa a las obligaciones del Estado en relación con el impacto del sector empresarial en los derechos del niño y № 17 relacionada con el derecho del niño al descanso, el esparcimiento, el juego, las actividades recreativas, la vida cultural y las artes. Observación General № 14, p. 3, disponible en: http://www2.ohchr.org/English/bodies/crc/docs/GC/CRC.C.GC.14_sp.pdf. 
de flexibilidad en su aplicación. El interés superior del niño, una vez evaluado y determinado, puede entrar en conflicto con otros intereses o derechos (por ejemplo, los de otros niños, el público o los padres). Los posibles conflictos entre el interés superior de un niño, desde un punto de vista individual, y los de un grupo de niños o los de los niños en general tienen que resolverse caso por caso, sopesando cuidadosamente los intereses de todas las partes y encontrando un compromiso adecuado. Lo mismo debe hacerse si entran en conflicto con el interés superior del niño los derechos de otras personas. Si no es posible armonizarlos, las autoridades y los responsables de la toma de decisiones habrán de analizar y sopesar los derechos de todos los interesados, teniendo en cuenta que el derecho del niño a que su interés superior sea una consideración primordial significa que los intereses del niño tienen máxima prioridad y no son una de tantas consideraciones. Por tanto, se debe conceder más importancia a lo que sea mejor para el niño" (lo destacado en cursiva es mío) ${ }^{51}$.

El interés de ambos padres, conforme a lo ya señalado, debe sopesarse al momento de establecer la regla de asignación de derechos de filiación por parte del juez. Ello conduce normalmente a que el juez pueda decretar el cuidado compartido con oposición de uno de los padres, sobre todo cuando ello es lo mejor que se puede hacer en concreto respecto del NNA (aspecto que excede el presente artículo); pero una vez realizada por el juez la asignación a favor de un padre por sobre el otro, el interés superior del niño confluye conjuntamente con el interés del padre no custodio. Por tanto, el juez concretizarlas facultades y derechos correspondientes al padre no custodio. El juez debe asegurar la participación del padre no custodio en la educación y crianza de sus hijos, salvo que el interés superior del niño clara y probadamente indique lo contrario. Esta forma de aplicar el principio del interés superior da lugar a lo que se ha denominado custodia conjunta, y es precisamente lo que establece el artículo 224 del CCch. Antes de entrar a analizar el Derecho chileno veamos las formas de custodia conjunta que se han establecido en el Derecho comparado, antes de la adopción del cuidado compartido como régimen legal privilegiado.

\section{Evolución del Derecho comparado hacia un sistema de igualdad de facultades y derechos de filiación entre los padres}

Los diversos ordenamientos jurídicos, como se apreciará a continuación, tratan de entregar al juez la mayor cantidad de atribuciones, que les permitan

\footnotetext{
${ }^{51}$ Observación General № 14, p. 3, disponible en: http://www2.ohchr.org/English/bodies/crc/docs/ GC/CRC.C.GC.14_sp.pdf, PP. 10-11.
} 
concretizar la participación de ambos padres en la crianza y educación de los hijos; pero estos esfuerzos se hacen conforme a la cultura jurídica concreta de los distintos Derechos, sin dejar de lado los importantes rasgos comunes de todos ellos. Así, algunos ordenamientos jurídicos comenzaron a evolucionar hacia sistemas de custodia conjunta, ampliando las facultades y derechos a favor del padre no custodio. Los Derechos que se analizan a continuación establecieron instituciones y figuras jurídicas, que permitieron a los jueces concretizar el interés superior del niño en su esfera de desarrollo de derechos.

\section{En los países del Common Law: un sistema de custodia conjunta y cuidado compartido}

En el Reino Unido, la Reforma de 1989 concede la parental responsibility al padre en los siguientes casos: a) El reconocimiento del hijo conjuntamente con la madre (art. 4 de la Ley de 1989, modificado por el art. 111 de la Ley de Adopción de 2002). b) Un acuerdo de responsabilidad parental (parental responsibility agreement). En estos acuerdos de reconocimiento, que se rigen por la Section 4 (1) (b) de la Ley de Adopción, participa un funcionario de la Corte como testigo y posteriormente debe registrarse en Principal Registry of the Family Division. c) Una orden de la Corte (parental responsibility order).

Este último supuesto está regulado en el artículo 4 (1) (a) de la Ley de 1989. La demanda debe ser presentada por el padre y es evaluada por la Corte, conforme al nivel de compromiso que éste ha demostrado con relación al hijo y lo razonable que es la petición ${ }^{52}$.

La Reforma introducida por la Ley de 1989 en el $R U$ fue primordial en el resguardo de los derechos del padre no custodio. La referida Ley derogó tanto el concepto de guardianship-que se deja para la designación a los terceros que ejercen los derechos de filiación sin ser padres-, como el de parental guardianship y estableció el concepto de parenthood, que corresponde indistintamente a la paternidad o maternidad, y parental responsibility ${ }^{53}$. Este concepto es fundamental en la referida Reforma y establece una responsabilidad conjunta, que se llena de un contenido determinado por un buiding block y un bundle of duties, es decir, por un conjunto de derechos y deberes de la infancia y adolescencia; pero además de ello exige que el Estado respete y promueva el

\footnotetext{
52 Probert (2009), p. 250.

53 A este respecto Bromley y Lowe señalan que: "in producing what the Department of Health's Introduction to the Children Act 1989 describes as a 'practical and consistent code' the 1989 Act embodies three fundamental changes of concept, namely, parenthood replacing guardianship as the primary concept, 'parental responsibility' replacing the concept of parental rights and duties and new powers to make residence orders rather than custody orders". BROMLEY\&LOWE (1992), p. 253.
} 
ejercicio de los derechos de filiación conjunto de los padres ${ }^{54}$. Y son los padres los que tienen un derecho preferente, con relación al Estado, para determinar la forma de educación y los valores de los hijos ${ }^{55}$. Este es un punto de vital importancia, porque, dado el conflicto entre los padres y el interés superior del niño, pudiera entenderse que el Estado puede optar exclusivamente por otorgar las facultades y derechos de filiación a uno de los padres; pero dicha posibilidad, en principio, le está vetada. El juez debe velar por que el derecho a la crianza y educación sea conjunto. Por tanto, el reto para el juez será establecer formas que compatibilicen dos formas de crianza y educación de los padres, aunque ellas no sean del todo compatibles. El juez no puede recurrir al interés superior del niño como un criterio de asignación de la crianza y educación indivisible, por el cual la decisión se le otorga a uno de los padres. En otras palabras, el juez al aplicar la ley debe velar por establecer mecanismos por los cuales concepciones diferentes de los padres, en torno a la crianza y educación de los hijos, sean respetadas.

El Derecho americano ha hecho un esfuerzo por separar $<<$ lo cotidiano $\rangle>$, que puede ser conjunto o no, de los demás derechos y facultades, que necesariamente son conjuntos. En este sentido se debe distinguir una custodia física del menor, que otorga al padre ciertos derechos y facultades inherentes a lo cotidiano, y otros aspectos que son necesariamente conjuntos y no dependen directamente de lo cotidiano. La delimitación de este imperceptible límite es de trascendental relevancia y su determinación es una de las labores fundamentales de los tribunales ${ }^{56}$.

\footnotetext{
${ }^{54}$ Bromley y Lowe traen a colación las influyentes palabras del profesor Hoggett con relación a esta ley: "the [Act] assumes that bringing up children is the responsibility of their parents and that the State's principal role is to help rather than to interfere. To emphasise the practical reality that bringing up children is a serious responsibility, rather than a matter of legal rights, the conceptual building used throughout the $[\mathrm{A}] \mathrm{ct}$ is "parental responsibility". This covers the whole bundle of duties towards the child, with their concomitant powers and authority over him, together with some procedural rights to protection against interference (...) It therefore represents the fundamental status of parents". BROMLEY \& LOWE (1992), p. 253.

${ }^{55}$ A este respecto se puede consultar a Probert, que señala: "it is however important to emphasize that the welfare of the child is not by itself sufficient to justify state intervention, reflecting another aspect of parental responsibility, namely the privilege of bringing up one's chi1dren without state interference. As Baroness Hale put it in R (Williamson) v Secretary of State for Education and Employment [2005] UKHL 5". PROBERT (2009), p. 241.

${ }^{56}$ En este sentido es destacable un fallo de la CS de New Jersey, que dispone: "under a joint custody arrangement legal custody -the legal authority and responsibility for making $<<$ major $>>$ decisions regarding the child's welfare- is shared at all times by both parents. Physical custody, the logistical arrangement whereby the parents share the companionship of the child and are responsible for $<<$ minor $>>$ day-today decisions, may be alternated in accordance with the needs of the parties and the children". De Wittety otros(2005), p. 480.
} 


\section{En Francia e Italia: un sistema de custodia conjunta y cuidado compartido}

En Francia, la Ley de 4 de junio de 1970 estableció un sistema de autoridad parental unilateral a favor de la madre, para los hijos no matrimoniales (exart. 374 del Code), y de guarda exclusiva para uno de los padres para los hijos matrimoniales (exartículo 373-2 del Code). En el caso de los hijos matrimoniales el padre no guardador tenía a su favor un régimen de visitas y vigilancia (exart. 372-2 del Code). Lentamente, vía jurisprudencia, se comenzaron a otorgar estos derechos al padre no custodio respecto de los hijos no matrimoniales. Este proceso, hacia una igualación de los derechos de los padres, se aceleraría con la promulgación de las Leyes de 22 de julio de 1987 y 8 de enero de 1993. La Reforma de 1987 fue de suma importancia por cuanto estableció un ejercicio conjunto de la autoridad parental, que recogía la guarda conjunta que ya había sido reconocida por la jurisprudencia de la Corte de Casación (D. 1984, J.53 y JCP. 1984.II.20163)57. En dicha Reforma se modificaría el artículo 374 del Code, estableciéndose un ejercicio conjunto respecto de la autoridad parental, independientemente de la convivencia de los padres. La Ley de 8 de enero de 1993 establecería el sistema actual por el cual la regla general es la autoridad conjunta, reservándose el ejercicio indistinto para los casos en que el juez lo decrete de forma excepcional conforme al interés superior ${ }^{58}$. Así, de acuerdo con los artículos 371-1, 371-4 y 372 del Code, la autoridad parental es conjunta, y comprende los deberes-facultades de velar por la seguridad, salud y moralidad del menor, para asegurar su educación y permitir su desarrollo como persona, y sólo excepcionalmente el juez puede obstaculizar el derecho del niño a mantener relaciones personales con sus padres en su solo interés ${ }^{59}$. Previo a esta regulación, el antiguo artículo 288 del Code, antes de su supresión por la Ley $N^{\circ} 305$, de 4 de marzo de 2002, relative à l'autorité parentale ${ }^{60}$, consagraba un deber-facultad de vigilanda del padre no custodio ${ }^{61}$.

\footnotetext{
${ }^{57}$ García destaca los buenos resultados que generó en la sociedad francesa la Reforma de 1987. García (1997), p. 167.

${ }^{58}$ La Ley de 23 de diciembre de 1985 establecería un régimen más igualitario para la administración de los bienes del hijo. Terré y Fenouillet (2005), pp. 962-968.

${ }^{59}$ Ver: https://www.legifrance.gouv.fr/affichCode.do?idArticle=LEGIARTI000006426462\&idSectionTA $=$ LEGISCTA000006136194\&cidTexte $=$ LEGITEXT000006070721\&dateTexte $=20160310$ [sitio visitado el 8 de marzo del 2015].

${ }^{60}$ Ver:http://legifrance.org/affichTexte.do;jsessionid=E4C4C3BBB8415D422759BE137FEF408C.tpdjo 09v_3?cidTexte=JORFTEXT000000776352\&idArticle=\&dateTexte=20121219 [sitio visitado el 13 de diciembre del 2012].

${ }^{61}$ La referida norma era del siguiente tenor: "el esposo al que la guarda de los hijos no le ha sido confiada, conserva el derecho de vigilar su desarrollo y educación, debiendo contribuir en proporción a sus recursos". En igual sentido, conforme al artículo $356.1^{\circ}$ del $C P$ francés, era obligación del padre,
} 
Antes del establecimiento de la autoridad parental compartida, a pesar de que el deber de vigilancia no fue definido por el Code, comprendía el control sobre el ejercicio del derecho de guarda en interés del hijo, y el otorgar información sobre su salud, educación, y actividades recreativas y atingentes a su vida personal ${ }^{62}$.

La regulación italiana es muy similar a la francesa por cuanto la Reforma de 2006 estableció la custodia compartida como régimen legal y judicial supletorio, autorizando al juez de forma excepcional a concederla indistinta, cuando el interés superior del niño lo exigiese (artículos 155 y 155 bis del Codice). En este sentido, el primer párrafo del artículo 155 bis del Codice es muy interesante por cuanto exige residencia efectiva respecto de ambos padres con los hijos, aunque estén separados. Así, este régimen se concibe como una custodia compartida más que una corresponsabilidad conjunta ${ }^{63}$.

Como es natural los regímenes precedentes no son tan relevantes con relación al Derecho chileno por cuanto establecen sistema de cuidado compartido, pero su evolución es muy importante respecto de nuestro Derecho. Así, en el estadio en que nos encontramos lo que el juez debe velar es por el establecimiento concreto de deberes/facultades del padre no custodio que vayan en beneficio de los hijos y que sean una manifestación del principio de igualdad de los padres.

\section{En España: evolución conceptual desde un sistema de derechos y facultades de filiación que consagra el ejercicio y la titularidad de la patria potestad conjunta y de la guarda y custodia indistinta, hacia un sistema de custodia conjunta y cuidado compartido}

A pesar de que algunas Comunidades Autónomas han establecido como regla general sistemas de autoridad parental o de guarda y custodia conjuntos ${ }^{64}$,

que ostenta el ejercicio de la patria potestad, comunicar las decisiones que tome en torno al menor y especialmente su cambio de domicilio; agregando el artículo 373-2-1, que "este padre (se refiere el no custodio) conservará el derecho y el deber de cuidar del sustento y educación del hijo. Habrá de ser informado sobre las decisiones importantes relativas a la vida de este último. Y deberá respetar la obligación que le impone el artículo 371-2" (lo destacado entre paréntesis y cursiva es mío).

${ }^{62}$ Se puede consultar jurisprudencia a partir del fallo del Tribunal de Gran Instancia de París de 23 de febrero de 1971.

${ }^{63}$ http://www.senato.it/leg/17/BGT/Schede/FascicoloSchedeDDL/ebook/42930.pdf, pp. 16-17.

${ }^{64}$ La Ley aragonesa $N^{\circ}$ 2/2010, de 26 de mayo, y la Ley catalana $N^{\circ}$ 25/2010, de 29 de julio, establecen la custodia compartida como régimen judicial supletorio. De este modo, conforme a la Ley aragonesa, el juez deberá otorgar el cuidado compartido a los hijos como régimen preferente en caso de desacuerdo de los padres (artículo $6.2^{\circ}$ de la Ley aragonesa). La Ley catalana faculta al juez para distribuir la responsabilidad parental de forma compartida. 
la legislación española consagra como regla general un sistema de guarda y custodia indistinta. Ello, sin perjuicio de que el juez puede conceder el cuidado compartido, aun con oposición de uno de los padres, previo informe favorable del Ministerio Fiscal (artículo 92.8 ${ }^{\circ}$ del CCE) ${ }^{65}$. El sistema, -aunque otorga, por regla general, la guarda y custodia a uno de los padres, conforme al interés superior (Ley 15/2005) 66 $^{6}$, establece facultades y derechos para el padre no custodio exclusivos -que se desprenden generalmente del ejercicio de la patria potestad (artículo156.5 del CCE) - y facultades y derechos de filiación que son necesariamente conjuntos. Ello se logra a través de la titularidad de la patria potestad que es conjunta, como los deberes-facultades de velar por los hijos, tenerlos en su compañía, alimentarlos y otorgarles una formación integral (artículo 154 del $C C E)^{67}$. Así, la forma en que se articulan los derechos y facultades de los padres impide que se establezca una primacía del padre custodio. Y ello se evita precisamente a través de la forma de concebir la titularidad y el ejercicio de la patria potestad como derechos necesariamente conjuntos ${ }^{68}$; pero esta técnica legislativa no ha estado exenta de inconvenientes. Y estos nacen de una cierta

\footnotetext{
${ }^{65}$ El problema de la igualdad de los padres en torno al sistema de asignación de derechos de filiación, también se presenta en los casos de guarda compartida, como destaca VILLAGRASA. Para el referido autor el sistema de guarda compartida no implica que, durante el periodo de guarda con el hijo, el progenitor que lo tenga consigo sea soberano para tomar decisiones referidas a la potestad, sino que sólo será responsable de su cuidado y de adoptar decisiones relativas a los actos cotidianos. VILLAGRASA, (2012), p. 97.

${ }^{66}$ De este modo, en el Mensaje de esta Ley se señala que: "consiguientemente, los padres deberán decidir si la guarda y custodia se ejercerá sólo por uno de ellos o bien por ambos de forma compartida. En todo caso, determinarán, en beneficio del menor, cómo éste se relacionará del mejor modo con el progenitor que no conviva con él, y procurarán la realización del principio de corresponsabilidad en el ejercicio de la potestad"; y el artículo 10 de la Ley que dispone: "El párrafo primero de la medida 1. ${ }^{a}$ del artículo 103 del Código Civil quedará redactado como sigue: «1. ${ }^{a}$ Determinar, en interés de los hijos, con cuál de los cónyuges han de quedar los sujetos a la patria potestad de ambos y tomar las disposiciones apropiadas de acuerdo con lo establecido en este Código y, en particular, la forma en que el cónyuge que no ejerza la guarda y custodia de los hijos podrá cumplir el deber de velar por éstos y el tiempo, modo y lugar en que podrá comunicar con ellos y tenerlos en su compañía»".

${ }^{67}$ Para Rabadán la pérdida de la titularidad de la patria potestad implica la pérdida de su ejercicio; pero la pérdida del ejercicio, como se desprende del art. $156.2^{\circ}, 4^{\circ}$ y $5^{\circ}$ del $C C E$, no implica la pérdida de la titularidad. Naturalmente esta distinción, aunque doctrinariamente clara, no lo es tanto para la jurisprudencia de los tribunales, por cuanto suele referirse a estas figuras confundiéndolas (STS, de 17 de junio de 1995). RABADÁN (2011), pp. 27-28.

${ }_{68}$ Para Rabadán: "la titularidad (se refiere a la patria potestad) atribuye una serie de facultades y deberes que conforman el contenido de la patria potestad y que a tenor del artículo 154 del Código Civil son velar por los hijos, tenerlos en su compañía, alimentarlos, educarlos y procurarles una formación integral, representarlos y administrar sus bienes. Pero la patria potestad estaría vacía de sentido si estas facultades y deberes no pudieran llevarse a la práctica, es decir, ejercerse. El ejercicio, por tanto, sería la puesta en práctica del conjunto de facultades y deberes que integran el contenido de la patria potestad (hay nota al pie)" (lo destacado entre paréntesis y en cursiva es mío). RABADÁN (2011), pp. 22-23.
} 
indefinición terminológica que lleva a entender que los derechos y facultades de filiación se centralizan en el padre custodio, a través de la asignación de la guarda y custodia exclusiva a favor de uno de los padres ${ }^{69}$. Delgado explica este problema, señalando que existe una confusión e indeterminación respecto del contenido de la patria potestad y a su relación con la guarda y custodia. Así, para el referido autor: "[e]s muy frecuente encontrarse con Profesionales del derecho, Jueces y Fiscales, Psicólogos de equipos psicosociales adscritos a los Juzgados de familia, que piensan que al cónyuge custodio le corresponde tomar la mayor parte de las decisiones relativas a sus hijos, precisamente porque tiene atribuida su guarda y custodia" ${ }^{\prime 70}$. Así, para Delgado esta confusión es fuente de enfrentamientos y sólo sirve para intensificar la exclusión del progenitor no custodio. A pesar de estas críticas la doctrina española ha podido establecer facultades y derechos para el padre no custodio, que llevan a calificar a dicho sistema como de cuidado conjunto o de corresponsabilidad.

\section{La Corresponsabilidad, establecida en el artículo 224 del CCch, como forma de concretizar las facultades y derechos del padre no custodio}

Una vez analizada la evolución del Derecho comparado, desde sistemas de asignación de facultades y derechos desnudos para el padre no custodio y la forma en que el Derecho comparado ha ido evolucionando hacia sistemas de cuidado compartido y custodia conjunta, se entrará a analizar la Ley № 20.680 con relación a la forma en que se articulan las facultades y derechos del padre no custodio.

\section{Establecimiento de un Derecho de la infancia basado en la coparentalidad y corresponsabilidad}

El Principio N N 6 de la Declaración de Derechos del Niño de 1959 y el artículo $9.3^{\circ}$ de la $C D N$, entre otros instrumentos internacionales ${ }^{71}$, reconocen el

\footnotetext{
${ }^{69}$ Una forma de evitar esta indefinición ha llevado a una parte de la doctrina española a señalar que la custodia no es exclusiva, sino indistinta. La diferencia entre ambas concepciones de la custodia es radical, y excede el presente trabajo, pero la custodia indistinta supone una custodia principal y otra accesoria. RoDA (2014), p. 133.

70 Delgado (2010), p. 231.

${ }^{71}$ El artículo $7^{\circ}$ de la Convención Europea sobre los Derechos del Niño, aunque naturalmente no es aplicable en Chile consagra el derecho del niño a ser cuidado por ambos padres en tanto sea posible. Este criterio se profundiza en el artículo 18, que establece que los Estados Partes deben reconocer el principio de que ambos padres tienen una responsabilidad común en relación a sus hijos e hijas. Lo anterior ha llevado a algunos autores a entender que en Europa lo que debe primar es la custodia compartida.
} 
derecho de los niños de crecer al cuidado de sus padres. El artículo $5.1^{\circ}$ de la $C D N$ dispone que los Estados Partes respetarán las responsabilidades, los derechos y los deberes de los padres o, en su caso, de los familiares o de la comunidad, según establezca la costumbre local. Además, la referida norma agrega que dicha autoridad debe ser ejercida en consonancia con la evolución de sus facultades, dirección y orientación para que el niño ejerza los derechos reconocidos en la Convención ${ }^{72}$. A este respecto también se puede consultar la Observación General № 14 (2013) del Comité de los Derechos del Niño de UN sobre el derecho del niño a que su interés superior sea una consideración primordial (artículo $3^{\circ}$, párrafo $1)^{73}$. La precedente regla establece que los Estados deben evitar separar a los hijos de su familia, sobre todo basándose en consideraciones de pobreza económica y material y que: "cuando la separación sea necesaria, los responsables de la toma de decisiones velarán por que el niño mantenga los lazos y la relación con sus padres y su familia (hermanos, familiares y personas con las que el niño haya tenido una relación personal estrecha), a menos que ello contravenga el interés superior del niño. Cuando se separa a un niño de su familia, en las decisiones que se adopten acerca de la periodicidad y la duración de las visitas y otras formas de contacto deben tenerse en cuenta la calidad de las relaciones y la necesidad de conservarlas (...) El Comité considera que las responsabilidades parentales compartidas suelen ir en beneficio del interés superior del niño. Sin embargo, en las decisiones relativas a la responsabilidad parental, el único criterio debe ser el interés superior del niño en particular.

Es contrario al interés superior que la ley conceda automáticamente la responsabilidad parental a uno de los progenitores o a ambos. Al evaluar el interés superior del niño, el juez debe tener en cuenta el derecho del niño a conservar la relación con ambos progenitores, junto con los demás elementos pertinentes para el caso" (lo destacado en cursiva es mío) ${ }^{74}$.

De lo anterior se aprecia la íntima relación entre los principios del interés superior del niño e igualdad de los padres. El Estado debe establecer y respetar

\footnotetext{
72 En este sentido son interesantes las palabras de Grant, Director Ejecutivo de UNICEF, que tras la ceremonia de firma de la Convención en Nueva York, el 26 de enero de 1990, manifestó: "la Convención ha dado prioridad a los niños en las agendas nacionales e internacionales. La Comunidad Internacional ha proporcionado una base firme para una nueva ética que define al niño como individuo con derechos inalienables no menos valiosos que los del adulto".

${ }^{73}$ Esta Observación tiene como precedente la Opinión Consultiva 17/2002 de la CIADH que fijaba el alcance precisamente del artículo $3^{\circ}$ de la $C D N$ en cuanto a que el interés superior del niño implica el pleno desarrollo de los menores y el ejercicio pleno de sus derechos, como criterio rector para la elaboración y aplicación de normas. Ver: http://www.corteidh.or.cr/docs/opiniones/seriea_17_esp.pdf.

${ }^{74}$ Observación General № 14, p. 3, disponible en: http://www2.ohchr.org/English/bodies/crc/docs/ GC/CRC.C.GC.14_sp.pdf, p.15.
} 
obligaciones, deberes y facultades conjuntos ${ }^{75}$, por cuanto ello es la mejor forma de desarrollar los derechos de la personalidad de la infancia. Esta es una regla general por cuanto la cercanía de uno de los padres es negativa para el desarrollo del niño, naturalmente el juez, conforme al principio del interés superior del niño, debe intervenir limitando sus facultades y derechos de filiación.

En consonancia con lo anteriormente señalado, por citar sólo un autor, Goldstein es de la opinión que: "[l]a ley supone, y debe suponer, que los niños son titulares del derecho a ser cuidados conjuntamente por sus padres" ${ }^{\prime \prime 6}$. Así, los distintos ordenamientos jurídicos deben consagrar figuras e instituciones, que permitan desarrollar facultades y deberes conjuntos o indistintos de los padres o del padre no custodio, cuyo objetivo sea consagrar facultades y derechos de ambos padres -independientemente de si el cuidado es por regla general indistinto o conjunto-.

La corresponsabilidad entendida de esta forma debe cumplir con los siguientes objetivos: (a) el desarrollo del niño como sujeto de derechos y (b) la protección de los niños en sus derechos. Para ello se debe recurrir a una aplicación e interpretación normativa que fomente el desarrollo de los derechos fundamentales de la infancia y que considere aspectos psicológicos y sociológicos. Estos últimos criterios tienden a lograr el más óptimo desarrollo emocional del niño y su bienestar, dada la realidad de ambos padres. A este respecto, dada nuestra regulación, se deben compatibilizar la asignación unilateral del cuidado personal con los deberes y facultades del padre no custodio, aunque la asignación no sea automática a uno de los padres. En otras palabras, se debe aplicar el actual sistema de filiación, conforme al interés superior del niño, que nos exige que ambos padres, aunque estén separados, participen "en forma activa, equitativa y permanente en la crianza y educación de sus hijos" (art. 224 del $C(C h)$ y ello se logra a través de tres medidas: (a) El establecimiento de deberes y facultades conjuntos que se desprenden de la crianza y educación conjunta; (b) El establecimiento de deberes y facultades propios sólo del padre no custodio que permiten una crianza y educación conjunta; (c) El permitir en casos excepcionales el cuidado personal compartido con oposición de un padre cuando con ello se obtenga el máximo bienestar del NNA.

En Chile, en los casos de desavenencia de los padres, los jueces deben, conforme a lo preceptuado en el nuevo artículo $225-2^{\circ}$ del $C$ Cch, optar por uno de ellos. Suponga el siguiente caso hipotético. En un proceso el juez debe otorgar el cuidado personal del hijo a la madre, porque en la especie la madre tiene unas habilidades parentales superiores a las del padre, de $80 \%$, y el padre sólo tiene

${ }^{75}$ Naturalmente que esto está en íntima relación con el principio de intervención mínima del Estado. Pinochet y Ravetllat (2015), pp. 81-86.

${ }^{76}$ Goldstein (2000), p. 115. 
$40 \%$ de habilidades parentales (artículos $225.4^{\circ}$ y $225-2$ del $C C$ Ch). Frente a este supuesto, el sistema chileno, aunque opte por la madre, no violará los derechos del niño sólo sí suma el $40 \%$ de las habilidades parentales del padre no custodio, lo que permitirá que el niño afronte el futuro con el apoyo de ambos padres, es decir, recibiría habilidades parentales por $120 \%$ y no sólo por $80 \%$. Por ello es deber del juez que el padre no custodio realmente participe: "...en forma activa, equitativa y permanente en la crianza y educación de sus hijos" (art. 224 del $C C$ h). Este caso nos demuestra cómo los principios del interés superior del niño y de la igualdad de los padres están, por regla general, entrelazados. A pesar que parte de la doctrina se ha mostrado crítica en torno a la nueva terminología ${ }^{77}$.

Conforme a lo ya señalado, los jueces, que son los Ilamados a aplicar la ley, deben fomentar que el padre no custodio participe en la formación y educación de sus hijos. En resumidas cuentas, se ha podido apreciar porque los dos principios, ordenadores de las deberes y facultades de filiación, respecto del padre no custodio, son el interés superior del niño y la igualdad de los padres.

\section{Breve Referencia a la historia fidedigna de la Ley No 20.680 y su sustentación en el principio de la igualdad de los padres}

El $P L$, se sustenta expresamente en los artículos $19, \mathrm{~N}^{\circ} 2$ de la $C P R$ y $17.4^{\circ}$ del Pacto de San José de Costa Rica (Convención Americana de Derechos del Hombre de 22 de noviembre de 1969), como normas fundantes de la Reforma, conforme a la Moción de los diputados Ascencio, Ojeda, Schilling, Venegas, y de las diputadas Goic, Muñoz y Saa, (Boletín No 7007-18). Ambas disposiciones se sustentan en el principio de igualdad de los padres. La Constitución establece el principio de igualdad ante la ley en los siguientes términos: "art. 19. La Constitución asegura a todas las personas: 2. La igualdad ante la ley. En Chile no hay persona ni grupos privilegiados. En Chile no hay esclavos y el que pise su territorio queda libre. Hombres y mujeres son iguales ante la ley.

Ni la ley ni autoridad alguna podrán establecer diferencias arbitrarias". Y a ello, el Pacto de San José agrega: "art. 17.4 Los Estados Partes deben tomar medidas apropiadas para asegurar la igualdad de derechos y la adecuada equivalencia de responsabilidades de los cónyuges en cuanto al matrimonio, durante el matrimonio y en caso de disolución del mismo. En caso de disolución, se

\footnotetext{
77 Para Tapia el término corresponsabilidad no es adecuado para nuestro Derecho civil que utiliza este término para la responsabilidad civil. A su vez, el referido autor destaca una cierta confusión en los artículos 224, que se refiere a la corresponsabilidad, y 225.2, que define el cuidado compartido con relación a lo señalado por el Sernam en la discusión de la ley. El Sernam sostenía que no se podía decretar residencias alternadas como forma de cuidado compartido, pero ello es contradictorio con lo señalado en las dos normas precedentes. TAPIA (2013), pp. 478-483.
} 
adoptarán disposiciones que aseguren la protección necesaria de los hijos, sobre la base única del interés y conveniencia de ellos" (lo destacado en cursiva es mío).

La Reforma, como puede apreciarse, está inspirada de forma exclusiva en el principio de igualdad de los padres ${ }^{78}$. Ello también se aprecia de la discusión del PL. En ella se señala expresamente que la coparentalidad: "se encuentra acorde con el principio de igualdad de ambos padres respecto de la crianza, establecimiento y educación de los hijos. Artículo 224 del Código Civil y artículos $1^{\circ}$ y $19 \mathrm{~N}^{\circ} 2$ de la Constitución Política de Chile, igualdad ante la ley"79. La coparentalidad es el gran sustento de la modificación de 2013, desde que expulsó la regla de la $<<$ superioridad materna $>>$ del ordenamiento jurídico chileno. El sustento de este principio, aunque es la igualdad de los padres, es una manifestación del interés superior del niño, por ende la Reforma está inspirada en principios constitucionales y civiles de carácter superior. La actual redacción del art. 224 se debió a una moción presentada por los senadores Alvear y Walker, la que, a pesar de la oposición del Sernam, fue aprobada en el Congreso. En cambio, la redacción del actual artículo 225 contó con el apoyo del Sernam, que se opuso tenazmente a facultar al juez para decretar una

78 El Primer Informe de la Comisión de Constitución de la Historia de la Ley № 20.680, señala: "sus fundamentos recuerdan que las disposiciones pertinentes del señalado cuerpo normativo, en especial, su artículo 224, establecen el derecho-deber de los padres de crianza y educación de los hijos por su calidad de tales y no por tener a su cargo el cuidado personal de los mismos, por lo que en caso de separación, no sólo mantiene este deber aquel de los dos que asume el cuidado personal, sino también el que es privado del mismo. Lo anterior guardaría relación con la Convención de los Derechos del Niño, cuyo artículo 18 dispone que los Estados deberán poner su máximo empeño en garantizar el reconocimiento del principio de que ambos padres tienen obligaciones comunes en lo que respecta a la crianza y desarrollo del niño, siendo su preocupación fundamental el interés superior del menor, como también con la Convención Americana sobre Derechos Humanos, que consagra en su artículo 17 la obligación de los Estados Partes de tomar medidas apropiadas para asegurar la igualdad de derechos y la adecuada equivalencia de responsabilidades de los cónyuges en cuanto al matrimonio, durante el matrimonio y en caso de su disolución. (...) Explica, en seguida, que, con el objetivo de reforzar la igualdad de responsabilidades parentales, otras legislaciones contemplan un sistema de tenencia compartida o custodia alternada, en cuya virtud el hijo convive con cada uno de los padres durante cierto tiempo, durante el cual uno de ellos ejerce el cuidado personal y el otro mantiene un régimen comunicacional. Agregan que si bien tal sistema presenta ventajas y desventajas, resulta de justicia considerarlo y apreciar su implementación caso a caso, teniendo en cuenta el interés superior del menor. Se expone, luego, el contenido de su propuesta, señalando que además de introducir el sistema compartido recién reseñado, se suprime la parte del artículo 225 que impide entregar el cuidado personal del hijo a aquel de los padres que no ha contribuido a su mantención mientras estuvo al cuidado del otro, pudiendo hacerlo, por cuanto, atendiendo al interés personal del menor, en términos generales, debe permitirse evaluar el caso particular de que se trate, puesto que puede ser mucho más nocivo asignar el cuidado personal del hijo a un tercero que a aquél de los padres que incumplió en los términos que trata este artículo". Ver: Historia de la Ley No 20.680, pp. 262-264.

${ }^{79}$ Ver: Historia de la Ley $N^{\circ} 20.680$, p. 283. 
forma de cuidado compartido con oposición en los términos planteados por el $P L^{80}$. En consecuencia se estableció como régimen legal supletorio el cuidado personal a cargo del padre que esté conviviendo con el menor (artículo 225.3 del $\left(C(c h)^{81}\right.$, y como regla de atribución judicial el interés superior del niño (artículo $225.4^{\circ}$ del CCch), estableciéndose en el artículo 225-2 del CCch las habilidades parentales como criterio de concreción de dicho interés ${ }^{82}$. Pero, sin lugar a dudas, lo más importante es que la Reforma estableció una $R D R$, que es una potente manifestación de la corresponsabilidad, en el artículo 229 del CCch.

En definitiva, lo que hasta el momento tenemos es un sistema de asignación exclusiva de cuidado personal, que para no transgredir el interés superior del niño exige establecer derechos y facultades a favor del padre no custodio. No es del caso analizar -por exceder con creces el presente trabajo- si dicha custodia, dada la redacción del art. 225 CCch, en realidad es indistinta más que exclusiva.

\section{Facultades y derechos del padre no custodio después de la Reforma implementada por la Ley $\mathbf{N}^{\circ} \mathbf{2 0 . 6 8 0}$}

Los artículos 224 y 229 del CCch establecen los criterios conforme a los cuales la jurisprudencia debería determinar los derechos y facultades del padre no custodio. A pesar de que es posible criticar estas normas ${ }^{83}$, la verdad es que ellas obedecen a la forma en que se regulan las instituciones en el Derecho

\footnotetext{
${ }^{80}$ A su vez, la indicación sustitutiva al PL que introduce modificaciones al Código Civil con el objeto de proteger la integridad del menor en caso de que sus padres vivan separados (Boletín № 5917 18), 30 de marzo de 2011, de la Cámara de Diputados, contemplaba la posibilidad de que el juez decretase un cuidado personal compartido, con oposición de uno de los padres. De esta forma se señalaba en la moción de la Cámara que: “(...) El juez podrá decretar el cuidado personal compartido por estas causales, siempre que se esté velando por el interés superior del hijo, ya que este principio es preferente al derecho de los padres", y se regulaba dicha figura en el artículo único, que introducía las siguientes modificaciones en el Código Civil: "a. Introdúcese, en el artículo 225, las siguientes modificaciones: (...) ii. Se incorporan los siguientes incisos (...): Velando por el interés superior del hijo, podrá el juez entregar el cuidado personal a ambos padres, cuando el padre custodio impidiere o dificultare injustificadamente, el ejercicio de la relación directa y regular del padre no custodio con el hijo o hijos, sea que ésta se haya establecido de común acuerdo o decretado judicialmente. También podrá entregarlo cuando el padre custodio realice falsas denuncias o demandas a fin de perjudicar al no custodio y obtener beneficios económicos...".

81 Esta norma ha sido

${ }^{82}$ Es por ello que Acuña sostiene que: "a partir de ahí, es posible afirmar que la corresponsabilidad parental debe ser ejercida con independencia del tipo de custodia que acordaron los padres o que decretó el juez". Y a pesar de que no señala en qué consistiría la corresponsabilidad parental, en los casos de cuidado personal indistinto, indica que "un buen régimen de relación directa y regular puede concretar también tal principio". AcUÑA (2013), pp. 45 y 46.

${ }_{83}$ Tapia critica fuertemente la Reforma por no haber establecido un catálogo de deberes/facultades conjuntos. TAPIA (2014), pp. 14-17. Rodríguez no critica la Reforma, pero la circunscribe al cuidado
} 
de familia, en que se establecen cláusulas generales de regulación, que deben concretizarse por la jurisprudencia ${ }^{84}$. Y a este respecto, conforme a lo estudiado, los tres grandes conceptos que establecen los artículos precedentes, con relación a los derechos y facultades del padre no custodio, son los siguientes:

a) El artículo 224 del CCch establece un criterio muy parecido a la titularidad y ejercicio conjunto de la patria potestad en el Derecho español cuando señala que, sin perjuicio de que el cuidado personal sea indistinto: "[t]oca de consuno a los padres, o al padre o madre sobreviviente, el cuidado personal de sus hijos. Éste se basará en el principio de corresponsabilidad, en virtud del cual ambos padres, vivan juntos o separados, participarán en forma activa, equitativa y permanente en la crianza y educación de sus hijos". Así, independientemente de la forma de asignación del cuidado personal, los padres deberán participar $<<$ en forma activa, equitativa y permanente en la crianza y educación de sus hijos $>>$. Lo que la norma hace es extraer del cuidado personal unilateral la crianza y educación del hijo. Nótese que la referencia de la primera parte del artículo es al "cuidado personal de sus hijos". De este modo lo que se establece es una forma de custodia indistinta más que exclusiva.

b) La extensión de los derechos y facultades del padre no custodio exige una participación activa, equitativa y permanente en la crianza y educación de sus hijos, es decir, en los aspectos cotidianos del niño. Como se ha analizado esta posición es concordante con lo que hoy ocurre en el Derecho comparado, ya sea a través del establecimiento de la corresponsabilidad compartida o de un sistema que obliga al padre no custodio a participar en los aspectos relacionados con lo cotidiano; pero es urgente que los tribunales concreticen estos derechos y facultades del padre no custodio.

c) La forma de determinar los derechos y facultades del padre no custodio, en caso de asignación unilateral del cuidado personal a un padre, está regulada en forma detallada en el artículo 229 del CCCh. Lamentablemente, hasta el momento, como se verá a continuación, no hay fallos que concreticen estos

personal compartido de común acuerdo, limitando las atribuciones de los jueces. Rodrícuez (2014), p. 80 .

${ }^{84}$ En este sentido nos inclinamos a favor de la posición de Illanes que estima que es posible aplicar sanciones al incumplimiento por parte del padre no custodio frente a los aspectos de la corresponsabilidad que la nueva normativa exige que se integren a la $R D R$. A ello se debe agregar que las reglas de incumplimiento (artículo 66 LPM) se deben aplicar a la infracción de deberes concretos por parte del padre no custodio. Y ello exige, en último término, que la sentencia determine los aspectos concretos de participación del padre no custodio en la educación y crianza de sus hijos, conforme a la exigencia de los artículos 224 y $229.3^{\circ}$ y $4^{\circ}$ CCCh.

ILLANES (2014), pp. 299-301. 
derechos y facultades del padre no custodio en los términos señalados por las normas precedentes.

\section{Breve análisis de la jurisprudencia de tribunales después de la Reforma implementada por la Ley $N^{\circ} \mathbf{2 0 . 6 8 0}$ en torno a la $R D R$}

La Reforma de 2013 estableció una amplia $R D R$ en el artículo $229.3^{\circ}$ y $4^{\circ}$ del CCch, íntimamente ligada con la corresponsabilidad consagrada en el artículo 224, del mismo cuerpo legal. A este respecto las normas fueron precisas en exigir, el artículo 224, que "ambos padres, vivan juntos o separados, participarán en forma activa, equitativa y permanente en la crianza y educación de sus hijos"; y, el artículo 229, que: "IP]ara la determinación de este régimen, los padres, o el juez en su caso, fomentarán una relación sana y cercana entre el padre o madre que no ejerce el cuidado personal y su hijo, velando por el interés superior de este último, su derecho a ser oído y la evolución de sus facultades (...) (inciso $3^{\circ}$ ) y "Sea que se decrete judicialmente el régimen de relación directa y regular o en la aprobación de acuerdos de los padres en estas materias, el juez deberá asegurar la mayor participación y corresponsabilidad de éstos en la vida del hijo, estableciendo las condiciones que fomenten una relación sana y cercana" (inciso $4^{\circ}$ ). Nótese la referencia expresa, del inciso precedente, a la participación y corresponsabilidad.

De este modo la $R D R$ es una extensión de una forma de custodia conjunta -no de cuidado compartido- que se manifiesta en tres aspectos: (a) El padre no custodio debe dar lugar a que el padre no custodio participe en forma activa, equitativa y permanente en la crianza y educación de sus hijos (artículo 224); (b) El juez debe velar por fomentar que el padre no custodio tenga una "relación sana y cercana", "velando por el interés superior de este último, su derecho a ser oído y la evolución de sus facultades" (artículo 229.3) y (c) El juez "deberá asegurar la mayor participación y corresponsabilidad de éstos en la vida del hijo, estableciendo las condiciones que fomenten una relación sana y cercana" (artículo 229.4\%).

Estos parámetros son los que deben determinar el contenido de la $R D R$, conforme a las denominadas cláusulas generales; pero, como se apreciará de las sentencias analizadas aleatoriamente a continuación, el régimen ordinario de $R D R$ simplemente corresponde a fin de semana por medio, no recurriéndose en los fallos a los criterios establecidos en la $C C C^{85}$ : (a) En I con I (2014): Tribunal

\footnotetext{
85 Se hace la prevención de que se escogieron al azar varias sentencias para ver si los tribunales de familia efectivamente están otorgando $R D R$ conforme a los artículos 224 y 229 del CCch. A este respecto cabe señalar que no interesan los motivos por los cuales se otorga el cuidado personal al otro padre (que podría ser otro aspecto a analizar). Asimismo, se ha tenido el cuidado de desechar las causas que decretan la inhabilidad de uno de los padres. En los casos tratados el juez pudo elegir
} 
de Familia de Pudahuel, 13 de abril de 2015 (demanda de cuidado personal), rol $N^{\circ} 1853$, se acoge la demanda y se fija la siguiente $R D R$ para la madre: "...a.Primera semana, el padre entregará a la niña en el domicilio materno el día sábado a las 11:00 horas y la retirará desde el mismo domicilio el día domingo inmediatamente siguiente a las 18:00 horas. b.- Segunda semana, en los mismos términos que la primera semana. c.- Tercera semana, día jueves la madre retirará a la niña desde el colegio al que asista en el horario de término de su jornada, siendo responsable de su asistencia a clases el día viernes, debiendo el padre retirar a la niña el día sábado inmediatamente siguiente a las 17:00 horas desde el domicilio materno. Si corresponde a día inhábil o día sin deber de asistencia escolar, el padre entregará a la niña en el domicilio materno el día jueves a las 20:00 horas y la retirará el día sábado inmediatamente siguiente a las 20:00 horas desde el domicilio materno" ${ }^{\prime 86}$. (b) En Q con S (2014): JF de Puerto Natales, 9 de febrero de 2015 (demanda de cuidado personal), rol № 150-2014, se desecha demanda, resolviendo en lo sustancial en torno al $R D R$ : "... se modifica el régimen comunicacional (...) en el sentido que será semanal, iniciándose el día viernes a las 17:00 horas hasta el domingo a las 18:00 horas, para lo cual el padre deberá viajar hasta el domicilio de los niños, comunicando a la madre, con al menos cinco días de anticipación, la efectividad de poder concurrir. Se entiende que este régimen está establecido en la medida que las posibilidades del padre, lo permita. Este régimen se verificará en esta Región". (c) En M con H (2015): Cuarto JF de Santiago, 30 de abril de 2015 (demanda de cuidado personal), rol $N^{\circ} 4516-2014$, se acoge la demanda (dado el desequilibrio de la madre), resolviendo: “...se adopta como medida cautelar, el régimen de relación directa y regular del siguiente modo: que doña (la madre) se relacionará con su hija (...) fin de semana por medio desde el día Viernes a las 18:00 horas y hasta el día Domingo a las 20:00 horas, comenzando dicha relación directa y regular a contar desde el viernes 8 de mayo de 2015 y así sucesiva y alternadamente" ${ }^{\prime \prime 7}$. (d) En S con B (2014): JF de Puerto Montt, 24 de mayo de 2014 (demanda de cuidado personal), rol $N^{\circ} 1.428-2013$, se desecha la demanda y fija la siguiente $R D R:$ "...entre el padre y su hijo se establece como régimen de relación directa y regular cada fin de semana por medio, en el que el padre retirará a su hijo los días viernes después de su jornada escolar y lo entregará los días domingo a las diecinueve horas. Además, se establece que el padre podrá mantener un

\footnotetext{
tanto a uno como al otro padre, por cuanto se estableció en las respectivas sentencias que el padre no custodio estaba habilitado para ejercer el cuidado personal. También se hace la prevención de que los fallos reproducen los aspectos sustanciales de la $R D R$ (lo que se denomina como régimen ordinario).

${ }^{86}$ La CA de Santiago confirmó por sentencia de 27 de mayo de 2015, rol № 1188-2015.

${ }^{87}$ La CA de Santiago confirmó por sentencia de 6 de julio de 2015, rol № Familia-1276-2015.
} 
régimen comunicacional con su hijo todos los días en los horarios que las partes deberán acordar" ${ }^{\prime 88}$. (e) En S con C (2014): Tercer JF de Santiago, 20 de abril de 2014 (demanda de aumento y modificación de $R D R$ ), rol № 1405-2013, se acoge parcialmente la demanda, resolviéndose: "A) Que el padre retirara a sus hijos fin de semana por medio, pernoctando con ellos el segundo de estos fines de semana retirándolos del hogar materno, en horario comprendido entre las 19 del día viernes hasta el día domingo, en que los restituirá a la casa materna a las 18:00 hrs. en período de clases y a las $20 \mathrm{hrs}$. si es período de vacaciones. $\mathrm{Si}$ el fin de semana que correspondiere incluyere un feriado, la visita de en estos casos incluirá el día festivo. B) Que el otro fin de semana, el padre podrá estar con sus hijos por el día sábado y domingo, ambos días de 11 a 20 hrs. día sábado y 11 a 18 hrs. día domingo y hasta las 20 hrs., en época de vacaciones". (f) En Z con Ch (2014): Juzgado de Letras y Familia de San Javier, 26 de marzo de 2014, rol No 377-2013, se acoge la demanda de cuidado personal contra una tía que mediante engaño obtiene transacción por la cual la madre le otorga el cuidado personal, fijándose como $R D R$ el siguiente régimen: “...se regula un régimen comunicacional entre el niño y su padre mediante el cual este adulto podrá vincularse con (si hijo) fin de semana por medio, en aquellos fines de semana donde no le corresponda vincularse con la madre, pudiendo el padre retirar al niño del domicilio de la guardadora el día viernes a las 19:00 horas y regresarlo al mismo domicilio el día domingo a las 18:00 horas, régimen que comenzará a regir el fin de semana siguiente a aquel en que el presente fallo quede ejecutoriado, no obstante, en caso de corresponderle al niño en aquel fin de semana vincularse con la progenitora, se iniciará el presente régimen el fin de semana siguiente".

\section{Conclusiones parciales}

a) La Reforma de 2013 se basa en el principio del interés superior del niño que vincula al de la igualdad de los padres, y no se inclinó por establecer como un sistema general de cuidado personal compartido, sino por un sistema de custodia conjunta. Así se desprende del principio de la corresponsabilidad consagrado en el artículo 224 del CCch. Pero, como ello no es suficiente, en el artículo $229.3^{\circ}$ y $4^{\circ}$, segunda parte, estableció el contenido de la corresponsabilidad en torno a la $R D R$. Esta es una técnica legislativa que establece una cláusula general que debe ser llenada concretamente por los Juzgados de Familia.

\footnotetext{
${ }^{88}$ La CA de Puerto Montt confirmó por sentencia de 25 de julio de 2014, rol Ingreso Corte № 88-2014. La casación presentada por el padre ante la CS también fue desechada (fallo de 20 de julio del 2015, rol Ingreso Corte No 23.113-2014).
} 
b) Las sentencias analizadas permiten dilucidar que los tribunales de familia aún no llenan de contenido las cláusulas generales contenidas en los artículos 224 y $229.3^{\circ}$ y $4^{\circ}$ del CCch por cuanto no establecen -dado el caso concreto que tienen que resolver- de qué forma el padre no custodio participa en la crianza y educación de sus hijos. Los fallos establecen una extensión temporal de la $R D R$ de no más que cuatro o cinco días al mes, no señalando de qué forma el padre no custodio participa en la crianza y educación de los hijos. En realidad las sentencias están estableciendo simplemente regímenes de visita. Así, de los casos que se analizaron, se aprecia una preferencia marcada por mantener los derechos y facultades de filiación en el padre custodio, excluyendo al padre no custodio. Por lo que sólo cabe concluir que la forma de aplicación de la Reforma establece facultades y derechos prácticamente desnudos para el padre no custodio.

\section{Conclusiones finales}

1. El Derecho de la infancia ha ido variando desde formas de asignación de custodia unilateral exclusiva a favor de uno de los padres -en un principio al padre, y luego a la madre- a formas de custodia indistintas en las cuales el padre no custodio debe participar en la formación de sus hijos.

2. La solución al problema precedente en el Derecho Comparado de la Infancia es transitar desde un sistema de asignación unilateral de deberes/ facultades de filiación, a favor de uno de los padres, a un sistema de ejercicio conjunto de facultades y derechos de filiación (custodia compartida). Ello se ha debido a que una de las aplicaciones más relevantes del principio del interés superior del niño es la igualdad de los padres, por cuanto dicha aplicación asegura que los niños recibirán la formación y apoyo de ambos progenitores.

3. Sin perjuicio de lo anterior, no necesariamente las formas de asignación de cuidado unilaterales son contrarias al interés superior. La asignación de las formas de custodia, conforme al principio del interés superior a favor de cualquiera de los padres, puede respetar el principio del interés superior del niño; pero exige el cumplimiento de tres premisas: La primera es que los tribunales asignen estos derechos conforme al interés superior del niño. La segunda es que no se debe establecer un sistema de facultades y derechos desnudos para el padre no custodio, sino uno de cuidado conjunto (entre nosotros un sistema de corresponsabilidad). La Reforma de 2013, a lo menos reglamentariamente, cumple con estas dos premisas. La tercera es que el juez pueda decretar la custodia compartida con oposición del padre, en casos excepcionales, conforme al interés superior del niño. 
4. Lo anterior se debe a que el cuidado unilateral debe concretizar el interés superior, conjuntamente con el principio de la igualdad de los padres, que se manifiesta en un sistema de corresponsabilidad. No es posible aplicar el interés superior del NNA, descontextualizado del interés de los padres, como se analizó. Y ello se debe fundamentalmente a que el principio de la igualdad de los padres permite un mejor desarrollo de los derechos de la infancia, al participar en la formación del NNA no sólo el padre más hábil, sino ambos. Así se desprende del Derecho comparado, de la discusión del $P L$ de la Ley $N^{\circ} 20.680$ y de las doctrinas precedentemente analizadas; pero no toda forma de corresponsabilidad exige el cuidado personal compartido. El cuidado personal compartido, como régimen legal privilegiando, es una opción legal que nuestro Derecho desechó; pero ello no permite obviar el cuidado personal compartido -aun con oposición de uno de los padres- en la medida que dicho régimen sea el más favorable para el NNA. El $P L$, de la actual Ley № 20.680, sólo desechó una forma específica de cuidado personal compartido con oposición.

5. El presente trabajo, de las tres premisas precedentemente señaladas, se detiene sólo en la segunda, que se estaría cumpliendo, a lo menos reglamentariamente, conforme a lo preceptuado en los artículos 224 y $229.3^{\circ}$ y $4^{\circ}$ del $C C C h^{89}$; pero del análisis de la jurisprudencia cabe concluir que los tribunales no han determinado el contenido de las cláusulas generales, en torno a los tres aspectos destacados con relación a los deberes/facultades del padre no custodio, que consagran las tres normas precedentes.

6. Los jueces tienen las herramientas jurídicas para poder determinar el contenido de deberes/facultades para el padre no custodio a través de los artículos 224 y $229.3^{\circ}$ y $4^{\circ} \mathrm{CCch}$, es decir, específicamente en la determinación del contenido de la $R D R$. Lamentablemente, hasta el momento, esta jurisprudencia no se ha desarrollado.

\footnotetext{
${ }^{89}$ La primera premisa también se estaría cumpliendo reglamentariamente en los artículos $225.4^{\circ}$ y $6^{\circ}$ y 225-2 del CCCh (faltaría analizar si los tribunales efectivamente están aplicando los criterios establecidos en la normativa precedente) y la tercera premisa no tendría una regulación expresa. Sin perjuicio de lo cual, la $C S$ se inclina por la negativa de dicha posibilidad, pero en casos en que la custodia compartida no era beneficiosa para los menores. Ver: Sentencia de la CS, de 17 de diciembre de 2015, rol Ingreso de la Corte № 6320-15 anuló un fallo de la CA de Coyhaique, de 7 de abril de 2015, rol Ingreso de la Corte № 8-2015. La referida sentencia de la CA había confirmado un cuidado compartido con oposición de un padre, ordenado por sentencia del Tribunal de Familia de Coyhaique, de 6 de febrero de 2015, rol № ${ }^{\circ}$-314-2014. El fundamento último del fallo anulatorio es que esta figura no procede en la especie dada la continua conflictividad de los padres.
} 
Acuña San Martín, Marcela (2013): "El principio de la corresponsabilidad parental", en: Revista de Derecho, Universidad Católica del Norte (Año 20, $\left.N^{\circ} 2\right)$, pp. 21-59.

Almeda Samaranch, Elisabet y Di Nella, Dino (2012): "Monoparentalidad y responsabilidad parental", en: Picontó Novales, Teresa y otros, La custodia compartida a debate (Madrid, Editorial Dykinson), pp. 101-130.

Barrientos Grandón, Javier (2011): Derecho de las Personas. El Derecho Matrimonial (Santiago, Editorial AbeledoPerrot, Thomson Reuters).

Bromley, P.M. y Lowe, N.V. (1992): Family Law (Londres, Dublin, Edimburgo, Editorial Butterworths).

Cajigal Cánepa, Ivana (2016): "La facultad de delegar el ejercicio de la Responsabilidad Parental", en: Cuadernos de doctrina judicial de la provincia de La Pampa aportes sobre el nuevo Código Civil y Comercial (I), (Argentina, La Pampa), (Vol. VIII, No abril), pp. 284-297.

Castán Tobeñas, José (1995): Derecho civil español común y foral (Madrid, Editorial Reus SA), Tomo V.

CATAlDI, Myriam (2015): "La noción de coparentalidad y el derecho de los hijos a vivir en familia". Disponible en: http://www.nuevocodigocivil.com/ wp-content/uploads/2015/06/La-noci\%C3\%B3n-de-coparentalidad-y-elderecho-de-los-hijos-a-vivir-en-familia-por-Myriam-M.-Cataldi.pdf [Visitado el 25/07/2016].

Cruz Gallardo, Bernardo (2012): La Guarda y custodia de los hijos en las crisis matrimoniales (Madrid, Editorial La Ley).

Del Vas González, J.M. (2009): "La potestà genitoriale en el Derecho Civil Italiano", en: Revista Crítica de Derecho Inmobiliario (Año 85, № 714), pp. 2.015-2.013.

Del Vas González, J.M. (2010): "Rottura della famiglia e interesse dei figli en el Derecho Civil Italiano", en: Revista Crítica de Derecho Inmobiliario (Año 86, No 717), pp. 209-231.

Delgado del Río, Gregorio (2010): La custodia de los hijos, La guarda compartida: opinión preferente (Pamplona, Editorial Thomson Reuters).

De la Válgoma, María (2013): Padres sin derechos, hijos sin deberes. El laberinto jurídico de la infancia (Barcelona, Madrid, Editorial Ariel).

De WITT, Gregory; SwISHeR, John y Wolf, Peter (2005): Understanding Family Law (San Francisco, USA, Editorial LexisNexis). 
Domínguez Hidalgo, Carmen (2005): "Los principios que informan el derecho de familia chileno: su formulación clásica y su revisión moderna", en: Revista Chilena de Derecho (Año 32, No 2), pp. 205-218.

García PASTOR, Milagros (1997): La situación jurídica de los hijos cuyos padres no conviven: Aspectos personales (Madrid, Editorial McGraw-Hill).

García PRESAS, Inmaculada (2013): La patria potestad (Madrid, Editorial Dikynson).

GoldsteIN, Joseph (2000): “¿En el interés superior de quién?, en: Beloff, Mary (compiladora), Derecho, infancia y familia (Barcelona, Editorial Gedia), pp.115-130.

Greeven Bobadilla, Nel (2014): Filiación. Derechos humanos fundamentales y problemas de su actual normativa (Santiago, Editorial Librotecnia).

Guilarte Martín-Calero, Cristina (2014): La concreción de interés del menor en la jurisprudencia del tribunal supremo (Valencia, Editorial Tirant lo Blanch).

HafeN, Bruce (1992): "Family Law symposium. Children's liberation and the new egalitarianism: Some reservations about abandoning youth to their "rights", en: Krausse, Harry D, Child Law. Parent, Child, and State (New York, Editorial New York University Press), pp. 113-168 y 605-658.

Herrera, Marisa (2015): Manual de las familias (Buenos Aires, AbeledoPerrot).

Herring, Jonathan; Probert, Rebeca y Gilmore, Stephen (2015): “Disputes over children", en: Herring, Probert y Gilmore, Family Law (London Editorial Palgrave), pp. 77-106.

EsPejO YAKSIC, Nicolás (2016): "El derecho a la vida familiar, los derechos del niño y la responsabilidad parental", en: Lepin Molina y Gómez de la Torre, Estudios de Derecho de Familia I (Santiago, Editorial Thomson Reuters), pp. 197-209.

Foster, Henry y Freed, Doris (1992): "Bill of rights for children", en: Krause, Harry D, Law. Parent, Child, and State (New York, Editorial New York University Press), pp. 3-35.

ILlANeS ValdÉs, Alejandra (2014): "El resguardo de la corresponsabilidad parental en la Reforma de la Ley No 20.680", en: Vidal, Severín y Mejías (editores), Estudios de Derecho Civil X (Santiago de Chile, Thomson Reuters), pp. 299-307.

Lathrop Gómez, Fabiola (2008): Custodia compartida de los hijos (Madrid, Editorial La Ley).

LATHROP GÓMEZ, Fabiola (2010): “(In) constitucionalismo de la regla de atribución preferente materna del cuidado personas de los hijos del artículo 255 del Código Civil chileno", en: Revista lus et Praxis (Año 16, No 2) pp. 147-184 
Lathrop Gómez, Fabiola (2011): "Bases para una reforma de las relaciones personales en Chile", en: Revista del magíster y doctorado en Derecho (Año 0, No 4), pp. 91-98.

Lepin Molina, Cristián (2014): "Los nuevos principios del derecho de familia", en: Revista Chilena de Derecho Privado (Año, № 23), pp. 9-55.

LinACERO De la Fuente, María (2006): “Leyes de familia y constitución: Ley 13/2005 de 1 de julio y Ley 15/2005", en: Revista de Derecho Privado (Año 80, $\left.N^{\circ} 2\right)$, pp. 33-82.

Martín, Alesi (2015): “Deberes y derechos de los padres e hijos afines (Modelos de duplicación y sustitución de la función parental en la familia ensamblada)", Supl. Esp. Nuevo Código Civil y Comercial de la Nación. Familia: Filiación y Responsabilidad Parental 20/05/2015, 197, La Ley (Cita Online: AR/DOC/1305/2015), pp. 44.

Medina, Graciela (2014): "La responsabilidad parental en el Código Civil y Comercial de la Nación", en: Revista de Derecho de las Familias y de las Personas, (Cita Online: AR/DOC/3797/2014), p. 2.

Merino SCheiHING, Francisco (1990): "Consideraciones acerca de las reformas introducidas por la Ley 18.802", en: Cuadernos de análisis jurídico (Año, № 15), pp. 9-35.

Notrica, Federico y Rodríguez, Mariana (2014): “Responsabilidad parental. Algunos aspectos trascendentales a la luz del Nuevo Código Civil y Comercial de la Nación. Saldando viejas deudas", en: Graham y Herrera (Directoras), Derecho de las familias, infancia y adolescencia. una mirada crítica y contemporánea, INFOJUS (en: http://www.colectivoderechofamilia.com/wp-content/uploads/2015/06/FN-MRI-Responsabilidad-Parental.Algunos-aspectos-trascendentales-a-la-luz-del-Nuevo-C\%C3\%B3digo-Civily-Comercial-de-la-Naci\%C3\%B3n..pdf), pp.13.

Picontó Novales, Teresa (2012): “Ruptura familiar y coparentalidad: un análisis comparado", en: Picontó Novales, Teresa, La custodia compartida a debate (Madrid, Editorial Dykinson) pp. 45-76.

Pinto Andrade, Cristóbal (2009): La custodia compartida, Colección práctica jurídica (Barcelona, Editorial Bosch S.A.).

Pinochet Olave, Ruperto y Ravetllat Ballesté, Isaac (2015): “El principio de mínima intervención del Estado en los asuntos familiares en los sistemas normativos chileno y español", en: Revista de Derecho de la Pontificia Universidad Católica de Valparaíso (Año 44, № 1), pp. 69-96. 
Polakiewicz, Marta (1998): "El derecho de los hijos a una plena relación con ambos padres", en: Los derechos del niño en la familia, Discurso y realidad. (Buenos Aires, Editorial Universidad), pp. 165-196.

Probert, Rebecca (2009): Cretney and Probert`s Family Law. (London, Sweet \& Maxwell.

RabadÁn SÁnchez-Lafuente, Fuensanta (2011): Ejercicio de la patria potestad cuando los padres no conviven (Pamplona, Editorial Thomson Reuters).

Roda y Roda, Dionisio (2014): El Interés del menor en el ejercicio de la patria potestad (España, Pamplona, Thomson Reuters, Aranzadi).

Rodríguez Pinto, María (2009): "El Cuidado Personal de Niños y Adolescentes en la Familia Separada: Criterios de Resolución de Conflictos de Intereses entre Padres e Hijos en el Nuevo Derecho Chileno de Familia", en: Revista Chilena de Derecho (Año 36, № 3), pp. 545-586.

RodríGuez PINTO, Sara (2014): “Nuevas normas sobre cuidado personal, relación directa y regular, y patria potestad en el Código Civil chileno. Reformas introducidas por la ley № 20.680 de 2013", en: Revista de Derecho de familia, (vol. I), pp. 77-101.

Ruisánchez Capelasteguı, Covadonga (2006): La privación de la patria potestad (Barcelona, Editorial Atelier).

TAPIA Rodríguez, Mauricio (2013): "Actualidad Legislativa. Comentarios a la reforma del cuidado personal de los hijos (Ley No 20.680)", en: Revista Chilena de Derecho privado (Año 2013, № 21), pp. 477-491.

Tapia Rodríguez, Mauricio (2014): "Comentarios críticos a la reforma del cuidado personal de los hijos (Ley No 20.680)", en: Revista de Derecho de familia, (vol. I), pp. 13-271.

Terré, F. y Fenouillet, D. (2005): Droit civil. Les Personnes. La Famille. Les Incapacité, Séptima edición (Paris, Editorial Dalloz).

Veloso Valenzuela, Paulina (1998): "Nuevos principios del derecho de familia en función, principalmente, de la normativa internacional que emana de los tratados de derechos humanos", en: Revista de Derecho de la Universidad Católica de Valparaíso ( No 19), pp. 35-56.

Villagrasa Alcaide, Carlos (2012): "La custodia compartida en España y en Cataluña: entre deseos y realidades", en: Picontó Novales, Teresa, La custodia compartida a debate. (Madrid, Editorial Dykinson), pp. 77-99.

Zannoni, Eduardo (1998): Derecho Civil, Derecho de Familia, segunda edición (Buenos Aires, Editorial Astrea), tomo II. 
Zarraluqui SÁnchez-Eznarriaga, Luis (2003): "El menor en las crisis familiares", en: LÁzARO, Isabel y MAYORAL, Ignacio, Jornada sobre Derecho de los Menores (Madrid, Editorial Universidad Pontificia Comillas), pp. 159-202.

Zarraluqui Sánchez-Eznarriaga, Luis (2013): Marco jurídico paterno-filial en las rupturas de parejas (Barcelona, Editorial Bosch), pp. 1.560.

\section{NORMAS JURÍDICAS CITADAS}

Código Civil argentino.

Código Civil chileno.

Código Civil español.

Código Civil francés.

Código Civil italiano (de 1942).

Código Civil y de Comercio argentino.

Constitución Política de Chile.

Constitución Política española.

Convención de Derechos del Niño.

Convención Interamericana de Derechos Humanos.

Ley de Filiación (Ley No 19.585/1998).

Ley de Matrimonio Civil (Ley No 19.947/2004).

Ley de Participación en los Gananciales (Ley No 19.335/1994).

Ley de protección de menores.

Ley de Protección de Menores (Ley No 16.618/2000).

Ley de Tribunales de Familia (Ley No 19.968/2004).

Ley No 11/1990 (España).

Ley sobre Violencia Intrafamiliar (Ley No 20.066/2005).

Pacto de San José de Costa Rica (Convención Americana de Derechos del Hombre de 22 de noviembre de 1969).

\section{JURISPRUDENCIA CITADA}

Corte Suprema 24 de junio de 2010.

Sentencia (Corte Suprema), de 16 de agosto de 2010, rol Ingreso Corte No 4.372-2010.

"Atala Riffo y niñas vs. Chile" (2012): Corte Interamericana de Derechos Humanos 24 de febrero de 2012. 
Sentencia (Tribunal Constitucional chileno), de 30 de mayo de 2013, rol № 2306-12.

"S con C" (2014): Tercer Juzgado de Familia de Santiago 20 de abril de 2014 (demanda de aumento de alimentos y modificación de relación directa regular).

"S con B" (2014): Juzgado de Familia de Puerto Montt 24 de mayo de 2014 (demanda de cuidado personal).

Tribunal Constitucional chileno 16 de junio de 2015.

Corte de Apelaciones de Puerto Montt 25 de julio de 2014.

"Q con S" (2014): Juzgado de Familia de Puerto Natales 9 de febrero de 2015 (demanda de cuidado personal).

"I con I" (2014): Juzgado de Familia de Pudahuel 13 de abril de 2015 (demanda de cuidado personal).

"M con H" (2015): Cuarto Juzgado de Familia de Santiago 30 de abril de 2015 (demanda de cuidado personal).

Corte de Apelaciones de Santiago 27 de mayo de 2015.

Corte de Apelaciones de Santiago 6 de julio de 2015.

Corte Suprema), de 20 de julio del 2015. 